\title{
The simultaneous occurrence of both hypercoagulability and hypofibrinolysis in blood and serum during systemic inflammation, and the roles of iron and fibrin(ogen)
}

\author{
Douglas B. Kell ${ }^{\star a}$ and Etheresia Pretorius*b
}

\begin{abstract}
Although the two phenomena are usually studied separately, we summarise a considerable body of literature to the effect that a great many diseases involve (or are accompanied by) both an increased tendency for blood to clot (hypercoagulability) and the resistance of the clots so formed (hypofibrinolysis) to the typical, 'healthy' or physiological lysis. We concentrate here on the terminal stages of fibrin formation from fibrinogen, as catalysed by thrombin. Hypercoagulability goes hand in hand with inflammation, and is strongly influenced by the fibrinogen concentration (and vice versa); this can be mediated via interleukin-6. Poorly liganded iron is a significant feature of inflammatory diseases, and hypofibrinolysis may change as a result of changes in the structure and morphology of the clot, which may be mimicked in vitro, and may be caused in vivo, by the presence of unliganded iron interacting with fibrin(ogen) during clot formation. Many of these phenomena are probably caused by electrostatic changes in the iron-fibrinogen system, though hydroxyl radical $\left(\mathrm{OH}^{\bullet}\right)$ formation can also contribute under both acute and (more especially) chronic conditions. Many substances are known to affect the nature of fibrin polymerised from fibrinogen, such that this might be seen as a kind of bellwether for human or plasma health. Overall, our analysis demonstrates the commonalities underpinning a variety of pathologies as seen in both hypercoagulability and hypofibrinolysis, and offers opportunities for both diagnostics and therapies.
\end{abstract}

Insight, innovation, integration

The Biological Insight of this manuscript is that although they are usually studied separately (and thus typically described in separate papers) there is a considerable body of literature showing that both hypercoagulability and hypofibrinolysis a re present in a large number of inflammatory, vascular diseases. This mplies that they share common causes. Similarly, although these names reflect the changed kinetics of clot formation and lysis, there is also c onsiderable e vidence that the resistance to fibrinolysis c omes because the nature (make-up and morphology) of the dot differs in these states. One established cause comes from the interaction of unliganded iron with fibrinogen. The Technological Innovation is the use of advanced microscopy techniques (including atomic force microscopy) to $\mathrm{m}$ easure these changes. The Benefit of Integration comes (i) from bringing together these two separate readouts with a suggested major cause, viz. iron dysregulation, and (ii) by showing their commonality a cross a range of inflammatory vascular diseases we demonstrate this as Integrative Biology.

\section{Introduction}

Although the formation of blood clots and their subsequent removal are typical responses to the occurrence of damage in blood vessels, ${ }^{1,2}$ and this may also be part of the innate immune system, ${ }^{3-7}$ a

\footnotetext{
${ }^{a}$ School of Chemistry and The Manchester Institute of Biotechnology, The University of Manchester, 131, Princess St, Manchester M1 7DN, Lancs, UK. E-mail:dbk@manchester.ac.uk; Tel: +44 (0)161 3064492

${ }^{b}$ Department of Physiology, Faculty of Health Sciences, University of Pretoria, Private Bag x323, Arcadia 0007, South Africa. E-mail: resia.pretorius@up.ac.za; Tel: +27 124202864
}

common cause of thrombosis or thromboembolism (the formation of a blood clot that obstructs blood flow) is an excessive tendency toward blood clotting known ${ }^{8}$ as hypercoagulability.

Thromboembolic diseases are caused when a blood vessel is obstructed by a blood clot (embolus), whether formed locally or by one that has been carried in the bloodstream from the site of its formation. Thromboembolic diseases include both venous thromboembolism and arterial thrombosis, and these are treated differently (both intellectually and therapeutically) (e.g. ref. 9-13).

Thromboembolic events are responsible for approximately $80 \%$ of human strokes, ${ }^{14}$ specifically a type of stroke caused by 
the interruption of blood flow to a part of the brain due to the slow formation of a blood clot along the lumen of an artery. Cryptogenic ischaemic strokes are now thought to comprise about $25 \%$ of all ischaemic strokes and there is evidence that most cryptogenic strokes are thromboembolic. ${ }^{15}$ The thrombus is thought to originate from any of several well-established potential embolic sources, including minor-risk or covert cardiac sources, veins via paradoxical embolism, and non-occlusive atherosclerotic plaques in the aortic arch, cervical, or cerebral arteries. ${ }^{15}$ However, the most significant cause of thromboembolic stroke is considered to be due to a complication of atrial fibrillation (fibrillation of the muscles of the atria of the heart causing arrhythmia). ${ }^{16,17}$

Sudden occlusion of a cerebral blood vessel by a thrombus or embolism initiates a complex process of events that include excitotoxicity, oxidative stress, microvascular injury, blood brain barrier dysfunction and postischemic inflammation that ultimately leads to cell death. ${ }^{18}$ Also, most pertinently, thromboembolic events are associated with a hypercoagulable state. ${ }^{19,20}$

A great many 'risk' factors (including both genetic ${ }^{21-28}$ and environmental or 'lifestyle', as well as those accompanying medical interventions $^{29-32}$ ) can contribute to this hypercoagulability, ${ }^{33-38}$ and understanding these (Fig. 1) and how they interact probably makes this a problem that is thus best considered using the tools and ideas (e.g. ref. 39-43) of systems biology. While many diseases of haemostasis also involve a tendency to haemorrhage and/or inadequate clot formation, our focus will be on those coagulopathies where the rate and/or nature of the clot formation are greater, and its relative resistance to fibrinolysis is less, than optimal. An overview of the manuscript is given in Fig. 2.

\section{Relationship between chronic inflammation and hypercoagulability}

While a precise definition of chronic inflammation is slightly elusive, and is usually based around the observation of changes in various ('inflammatory') cytokines (e.g. ref. 44-46), there is abundant evidence that one of its hallmarks (or at least an extremely common co-existence in many circumstances) is a hypercoagulable state of some kind (e.g. ref. 10, 47-79).

Consequently, as we shall see, the long lists of inflammatory diseases that are additionally associated with iron dysregulation (e.g. ref. 80-85) are also those in which a hypercoagulable and/or hypofibrinolytic state may be observed.

\section{The healthy clotting cascade, mainly focussing on the thrombin pathway and on factor XIII crosslinking}

During healthy (normal) blood clotting, there are both 'intrinsic' and 'extrinsic' pathways (reviewed e.g. in ref. 86-88), but both converge on terminal steps in which prothrombin is converted

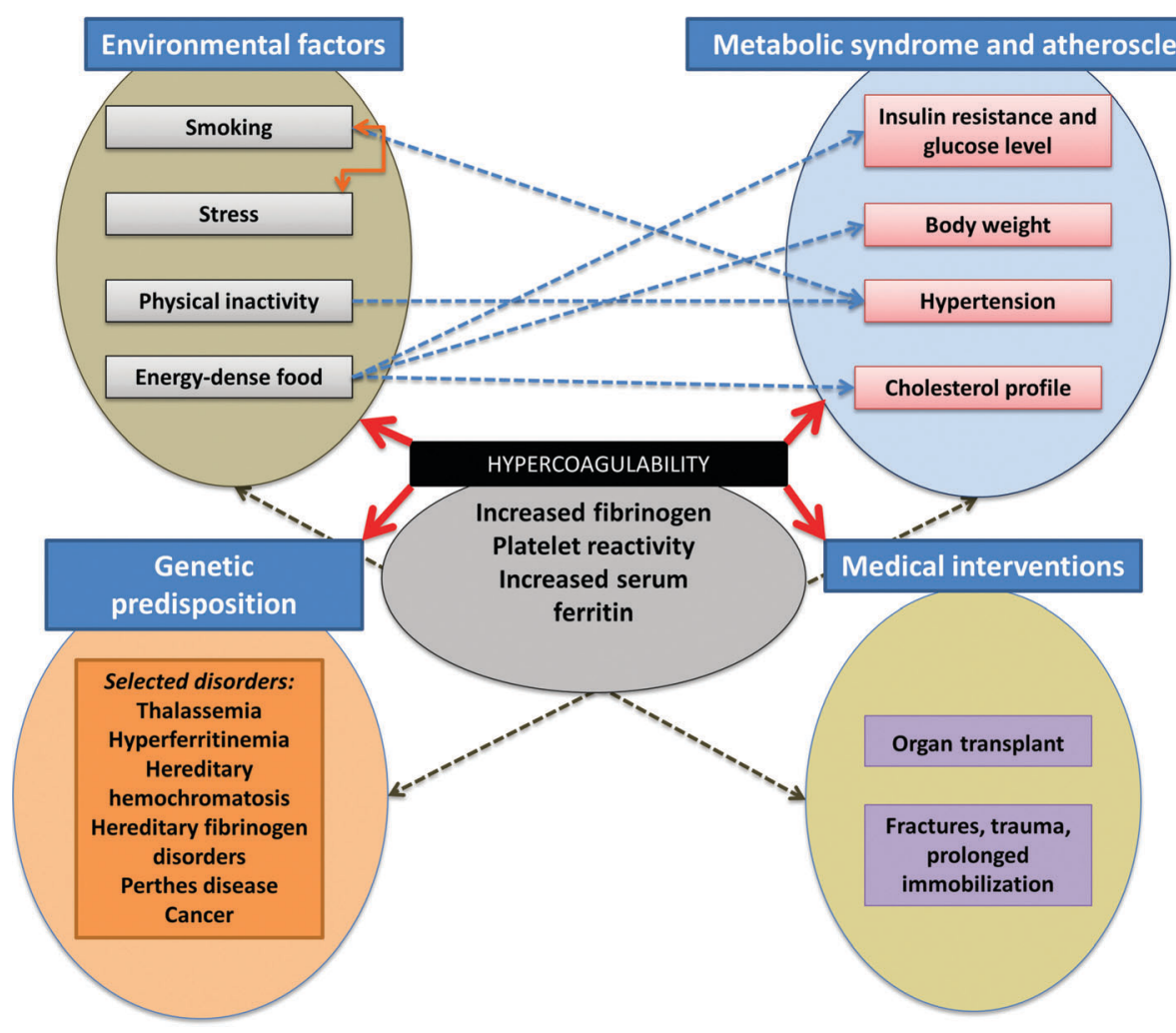

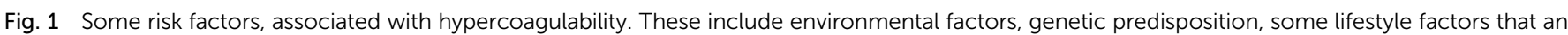
individual may have control over, potentially causing metabolic syndrome and atherosclerosis, as well as medical interventions. 


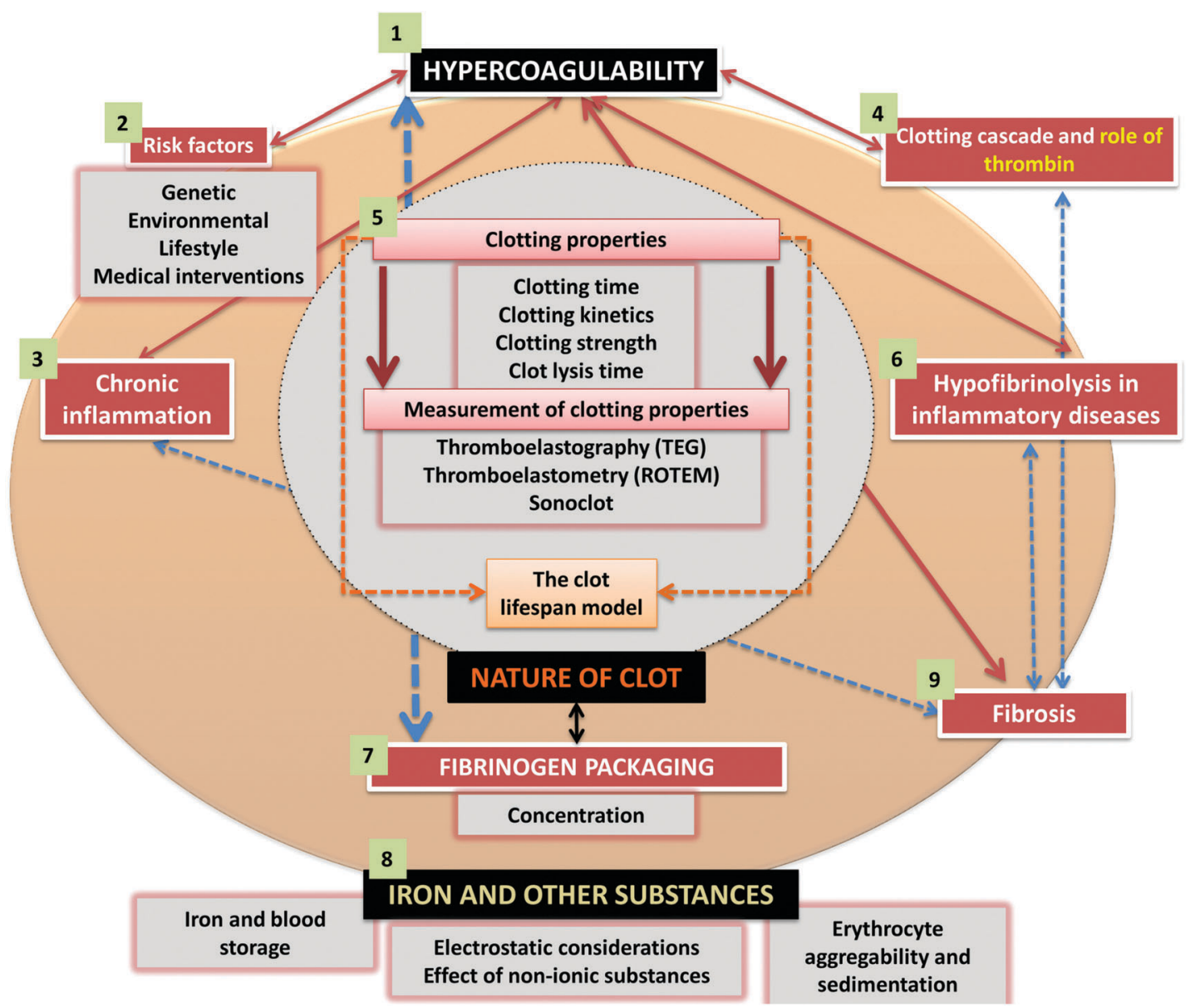

Fig. 2 An overview of the manuscript. The first focus of the manuscript is hypercoagulability (1). We discuss risk factors (2) and chronic inflammation (3), and how the clotting cascade (4) is changed during hypercoagulability. We also focus on clotting properties that are measurable using the current leading methods of thromboelastography (TEG), thromboelastometry (ROTEM) and Sonoclot technology (5). We show how this provides insight into hypofibrinolysis associated with inflammation (6) and how fibrinogen packaging (7) is changed during inflammation. Here we also discuss various substances and molecules (8) that may influence clot structure and also the relationship between hypercoagulability and fibrosis (9).

to thrombin followed by the thrombin-catalysed conversion of individual molecules of the soluble protein fibrinogen, with the release of two fibrinopeptides, to an insoluble, multimolecular complex of these molecules in the form of fibrin, the chief component of the blood clot. Thrombin also activates factor XIII to produce factor XIIIa, which catalyses intermolecular crosslinks between fibrin fibrils to stabilise the clot so formed (e.g. ref. 89-91).

A useful series of systems biology clotting models has been produced by Duffull and colleagues (e.g. ref. 92-96). Those of Wajima et al..$^{93}$ are available at the Biomodels database, ${ }^{97-99}$ and are most easily accessed in $\mathrm{SBML}^{100,101}$ form via the useful summary and commentary produced by Michael Schubert at http://www.ebi.ac.uk/biomodels-main/static-pages.do?page=Model Month\%2F2011-07. Biomodels 338, 339 and 340 pertain at the Biomodels database. Biomodel 338 mimics the extrinsic pathway, where deficiencies affect the prothrombin time (PT), while Biomodel 339 includes the intrinsic pathway that allows simulation and calculations that mimic the results of the activated partial thromboplastin test (aPTT). (Biomodel 340 is concerned with the effects of warfarin.)
Although most modern models of coagulation incorporate the role of cells, ${ }^{1,87,102,103}$ we shall concentrate here on the strippeddown terminal elements of the extrinsic (and common) pathway, where thrombin plays a crucial role in initiating the polymerisation of fibrinogen. These terminal processes, that are our focus here, are shown in Fig. 3, along with the normal (as seen in healthy individuals) degradation pathway of the fibrin via (fibrino)lysis catalysed by plasmin formed from the tissue plasminogen activator-catalysed activation of plasminogen.

\section{The viscoelastic measurement of clotting properties ex vivo: thromboelastography, thromboelastometry, Sonoclot and others}

The importance of understanding clot formation and degradation has led to the development of a considerable variety of assays for these processes (e.g. ref. 104-108). Most of these 


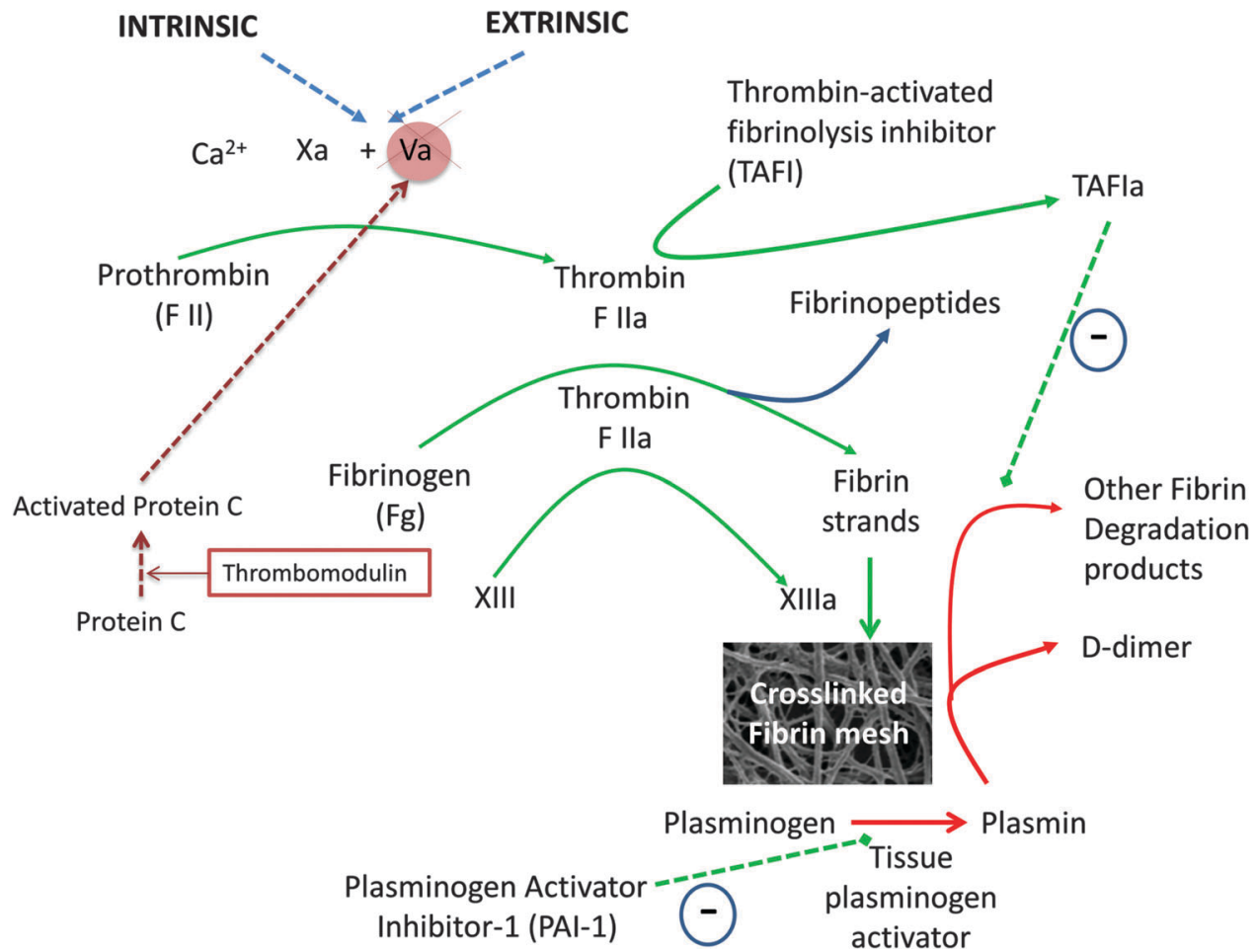

Fig. 3 The latter stages of the various coagulation pathways, showing places where thrombin plays a crucial role in initiating the polymerisation of fibrinogen.

methods are either optical or rheological/viscoelastometric in nature, and a number of commercial instruments exist. Some use plasma rather than whole blood, but plasma-based coagulation tests like prothrombin time (PT) and activated partial thromboplastin time (aPTT) have been seen as not entirely appropriate for monitoring coagulopathies, ${ }^{109}$ with a move to analyse whole blood and using methods that determine the viscoelastic properties directly. Nonetheless, PT and aPTT are pre-eminent in the clinic.

Viscoelastic haemostatic methods ${ }^{110}$ include thromboelastography (TEG), ${ }^{109,111-114}$ thromboelastometry (ROTEM) ${ }^{112,114-116}$ and the Sonoclot ${ }^{117-119}$ instruments. Some comparisons have been made, ${ }^{106,109,112-114,120-124}$ to the effect that results can be reasonably comparable in some circumstances but for detailed studies of specific effects it is probably wise to standardise on a particular instrument or technique.

\section{Thromboelastography, thromboelastometry and Sonoclot instruments}

In a typical thromboelastograph (a modern version is the Haemoscope) or rotational thermoelastometer (ROTEM), clotting is initiated and a trace generated where the ordinate represents the viscosity and the abscissa time. The differences are mainly as to whether a pin or the cup containing the blood is what is moved, and terminologies differ slightly according to Table 1 (based on ref. 106). Fig. 4 shows a schematic representation of a typical TEG and ROTEM readout (A), as well as viscoelastic haemostatic assay (VHA) tracings of a typical healthy trace (B)

Table 1 Terminologies of the variables measured in the TEG, ROTEM and Sonoclot instruments. Based on ref. 106,109 and 125

\begin{tabular}{|c|c|c|c|}
\hline Parameter & TEG & ROTEM & Sonoclot \\
\hline \multicolumn{4}{|l|}{ Clot time } \\
\hline Period to $2 \mathrm{~mm}$ amplitude & $R$ (reaction time, $\min$ ) & CT (clotting time, s) & ACT (activated clotting time, s) \\
\hline \multicolumn{4}{|l|}{ Clot kinetics } \\
\hline Period from $2-20 \mathrm{~mm}$ amplitude & $\begin{array}{l}K \text { (kinetics) } \\
\alpha \text { (slope between } R \text { and } K \text { ) }\end{array}$ & $\begin{array}{l}\text { CFT (clot formation time) } \\
\alpha \text { (slope of tangent at } 2 \mathrm{~mm} \text { amplitude) }\end{array}$ & $\begin{array}{l}\mathrm{CR} \text { (clot rate, } \mathrm{U} \mathrm{min}^{-1} \text { ) } \\
\mathrm{TP} \text { (time to peak, } \mathrm{min} \text { ) }\end{array}$ \\
\hline \multicolumn{4}{|l|}{ Clot strength } \\
\hline Maximum strength & MA (max amplitude) & MCF (max clot firmness) & PA (peak amplitude, U) \\
\hline Clot elasticity & $\mathrm{G}$ & MCE (max clot elasticity) & \\
\hline \multicolumn{4}{|l|}{ Clot lysis } \\
\hline Lysis (at fixed time) & $\begin{array}{l}\text { Ly30, Ly60 (amplitude reduction } \\
\text { 3/60 min after MA) }\end{array}$ & $\begin{array}{l}\text { CL30, CL60 (amplitude reduction } \\
\text { 30/60 min after MCF) }\end{array}$ & \\
\hline
\end{tabular}



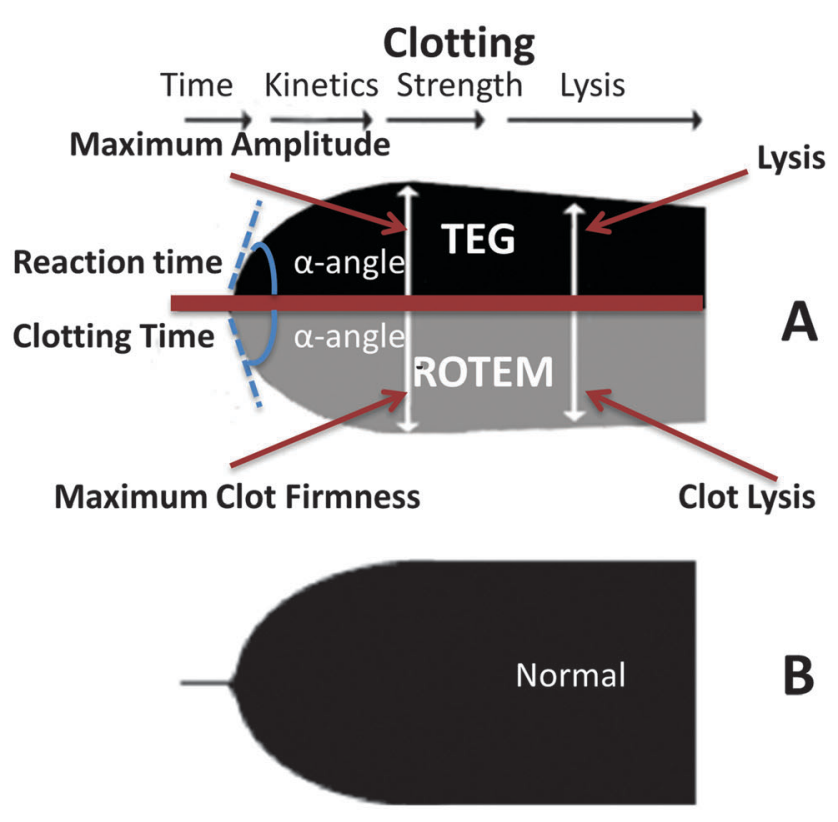

B
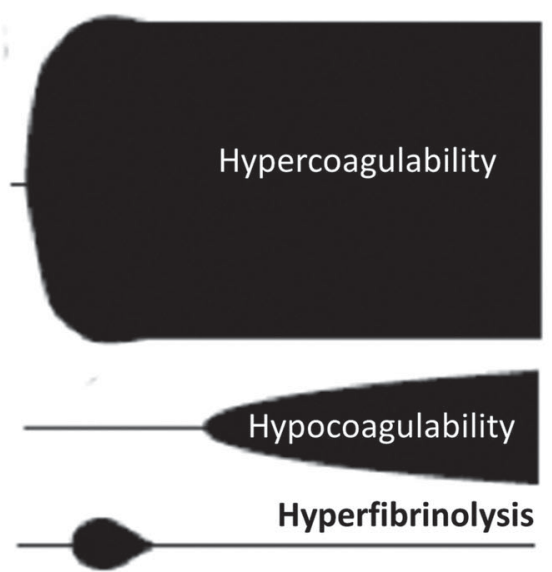

Hypofibrinolysis

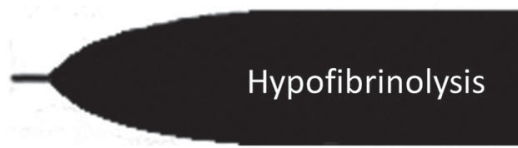

E

$\mathbf{F}$

Fig. 4 (A) Diagram comparing thromboelastography (TEG) with thromboelastometry (ROTEM), showing clotting/reaction parameters, including time, kinetics, strength and lysis of the clot. (B to F) Schematic representation of various viscoelastic haemostatic assay ( $\mathrm{VHA}$ ) tracings: (B) normal (healthy); (C) hypercoagulability; (D) hypocoagulability; (E) hyperfibrinolysis; and hypofibrinolysis (F). This diagram is based on a version in ref. 109.

versus hypercoagulability (C), hypocoagulability (D), hyperfibrinolysis (E) and hypofibrinolysis (F).

A slightly different principle is embodied in the Sonoclot instruments, in that the viscoelastic probe vibrates vertically, ${ }^{118}$ and the shape of the trace is somewhat different, producing a 'signature' with various peaks ${ }^{106,125-127}$ (Fig. 5).

We compare typical reference values for clotting time, clot kinetics and clot strength for the TEG, ROTEM and Sonoclot in Table 2.

\section{The clot lifespan model}

A specific TEG assay that focuses rather more on the clot itself has been developed by Nielsen and his colleagues, and is

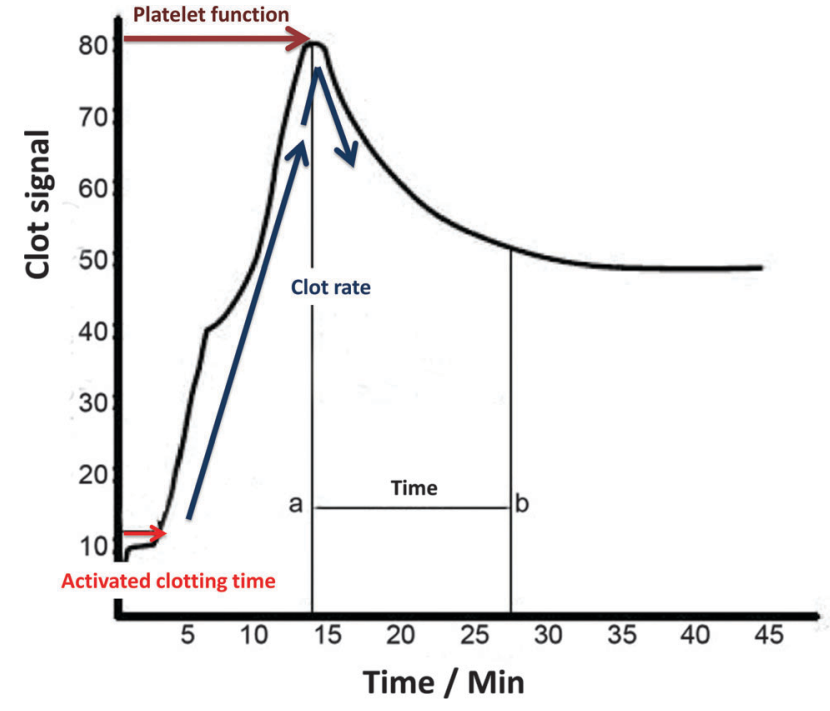

Fig. 5 A typical Sonoclot signature, adjusted from ref. 106 and 507.

known as the clot lifespan model ${ }^{129-132}$ (Fig. 6). It purposely combines a standardized clotting stimulus such as the tissue factor with a fibrinolytic stimulus such as the tissue type plasminogen activator to assess clot growth and disintegration via changes in clot resistance under the same incubation conditions. Its attraction from the present perspective is that it can assess both hypercoagulability and hypofibrinolysis in the same samples while admitting a reasonably swift assay time $(\sim 30 \mathrm{~min})$. In contrast to conventional TEG parameters, it also has the advantage of measuring the functionally relevant ${ }^{133,134}$ clot resistance directly. ${ }^{135}$

We also note a number of approaches to the development of coagulometry based on the measurement of the passive electrical properties of the sample, ${ }^{136-142}$ a strategy that we ourselves have found useful, ${ }^{143}$ with radio-frequency measurements of cellular properties having a particular value. ${ }^{144-147}$ Finally, fibrin scatters light much more than does fibrinogen such that turbidimetry is often used to detect its formation (e.g. ref. 148-153), and a number of more specialist coagulometric instruments based on optical (e.g. ref. 154) or other ${ }^{155-161}$ properties have been proposed (see Table 2).

\section{The relationship between hypercoagulability and hypofibrinolysis in selected inflammatory diseases}

Hypercoagulability refers to the likelihood of or tendency towards making a clot, while hypofibrinolysis refers to a decreased tendency to remove it. Clearly either or both could be seen as coagulopathies. This said, and although they are usually studied separately, the common co-occurrence (e.g. Table 3 and ref. 162) of hypercoagulability and hypofibrinolysis can be interpreted to mean that both can have the same cause. Similarly, although the distinction (and their naming) reflects the changed kinetics of clot formation and lysis, there is also considerable evidence that the thermodynamics, i.e. properties related to the nature (make-up and morphology) of the clot differs in these states. (We note that sometimes 
Table 2 Typical references values for clotting parameters of healthy blood and plasma as assessed using three different instruments. Based on ref. 106, 125 and 128. Note that the Sonoclot range varies considerably depending on whether activation includes glass beads

\begin{tabular}{llll}
\hline Parameter & TEG & ROTEM & Sonoclot \\
\hline Clotting time & $\begin{array}{l}\text { Whole blood 4-8 min } \\
\text { Citrated kaolin 3-8 min }\end{array}$ & Citrated intrinsic 137-246 s, extrinsic 42-74 s & 137-353 s \\
Clot kinetics & $\begin{array}{l}\text { Whole blood 1-4 min } \\
\text { Citrated kaolin 1-3 min }\end{array}$ & Citrated intrinsic 40-100 s, extrinsic 46-148 s & CR 7.6-36 U min ${ }^{-1}$ \\
& & & TP 5.2-15.2 min
\end{tabular}

Clot strengthening

Whole blood $\alpha 47^{\circ}-74^{\circ}$ Citrated kaolin $\alpha 55^{\circ}-78^{\circ}$

Citrated intrinsic $71^{\circ}-82^{\circ}$, extrinsic $63^{\circ}-81^{\circ}$

Maximum strength

Whole blood 55-73 $\mathrm{mm}$ Citrated kaolin 51-69 mm

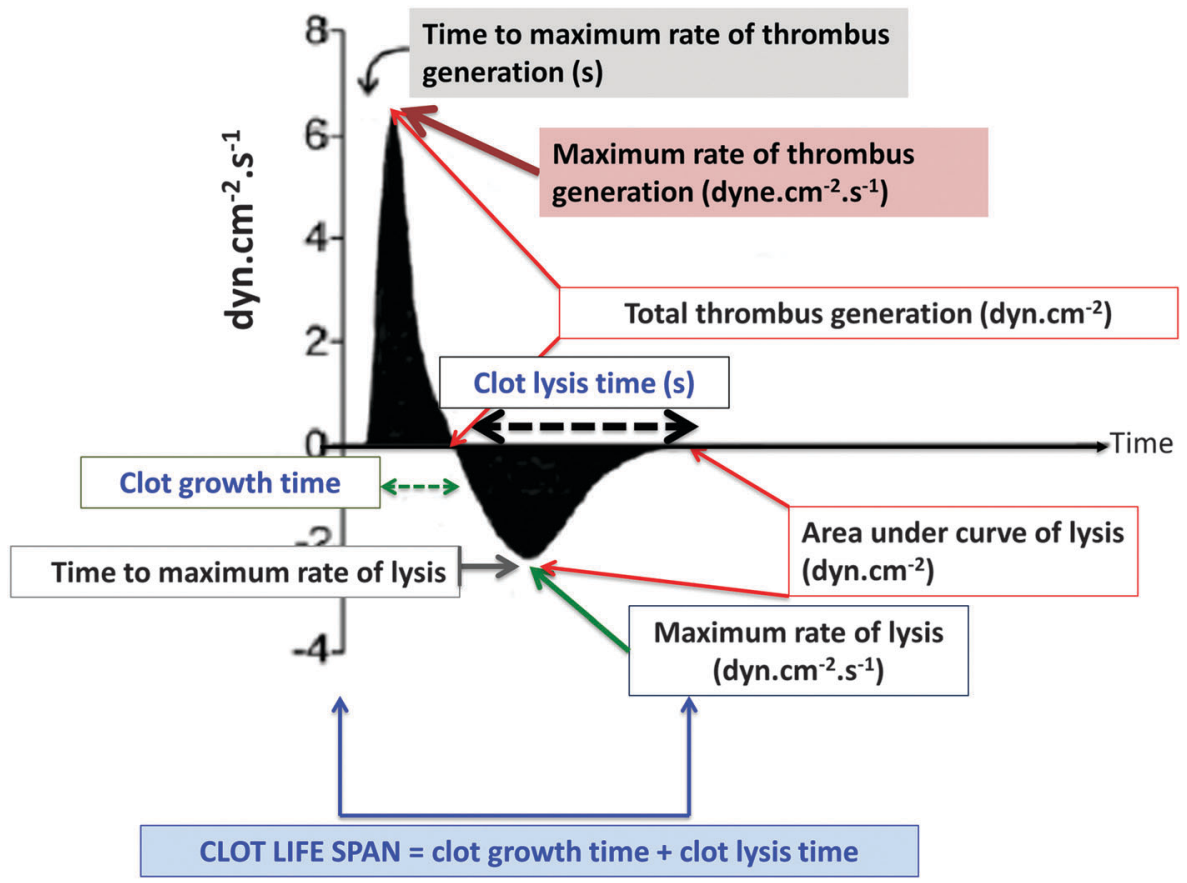

Fig. 6 The clot lifespan model developed by Nielsen and colleagues. ${ }^{129-132}$

Table 3 The co-occurrence of hypercoagulation and hypofibrinolysis in some selected diseases

\begin{tabular}{lll}
\hline Disease & $\begin{array}{l}\text { Some references showing blood } \\
\text { hypercoagulability }\end{array}$ & $\begin{array}{l}\text { Some references showing reduced clot permeability } \\
\text { or decreased susceptibility of clot to (fibrino)lysis }\end{array}$ \\
\hline Alzheimer's disease & 58 and $164\left(\right.$ but contrast $\left.{ }^{165}\right)$ & $166-171$ \\
Cancer & $23,172-186$ & 23,187 and 188 \\
Cardiovascular disease & $72,73,79,189-198$ & $25,162,191,192,199-211$ \\
Chronic obstructive pulmonary disease & $212-214$ & 215 \\
Cushing's syndrome & $216-222$ & 216,217 and 220 \\
Deep vein thrombosis & $7,188,223$ and 224 & $162,188,223,225$ and 226 \\
Diabetes mellitus, type 2 & $51,227-233$ & $34,206,228,230,232,234-241$ \\
Heart failure & 61,242 and 243 & 244 \\
Inflammatory bowel disease & $59,70,245-252$ & $246,253-256$ \\
Metabolic syndrome & $257-260$ & 25 and 258 \\
Pre-eclampsia & $261-265$ & 264 and 266 \\
Pulmonary embolism & 153 & 188,224 and 267 \\
Retinal vein occlusion & 268 & 162,268 and 269 \\
Rheumatoid arthritis & $270-276$ & 273 and 274 \\
Sepsis & $277-284$ & $277-280$ and 284 \\
Stroke & $56,194,195,285-291$ & $63,152,162,292-299$ \\
Systemic lupus erythematosus & 300 and 301 & 266,302 and 303 \\
Thromboembolism & $304-307$ & $307-310$ \\
Transient ischaemic attacks & $56,290,291$ and 311 & 63 and 295 \\
Trauma & $307,312-319$ & $315,320-322$
\end{tabular}


fibrinolysis is assessed via $\mathrm{D}$-dimer formation, ${ }^{163}$ but that when this is increased one cannot normally tell whether that is due to an increase in fibrinolysis or simply because there had previously been hypercoagulation.)

Note that in the case of $\beta$-thalassaemia there is a particularly noticeable amount of hypercoagulation ${ }^{323-335}$ but that fibrinolysis seems to be enhanced, ${ }^{324,336,337}$ albeit not by enough to overcome the hypercoagulation. The same seems to be true of psoriasis ${ }^{66,338-340}$ and of asthma. ${ }^{341-345}$ Interestingly, we have been unable to find any direct literature evidence for or against the role of hypercoagulability and/or hypofibrinolysis in the case of hereditary haemochromatosis, despite the fact that it is a well-known iron overload disease. ${ }^{346}$ DIC may be regarded as a contributor to a variety of syndromes, e.g. sepsis ${ }^{347}$ and multiple organ failure. ${ }^{78}$ There are also considerable changes in the coagulation variables during both healthy and compromised pregnancy. ${ }^{348-351}$ Finally, although we have listed the various diseases separately, there are a considerable number of comorbidities, such as IBD/cardiovascular events ${ }^{197}$ or chronic infection/multiple effects, ${ }^{352}$ as expected for multiple diseases with a broadly common cause. ${ }^{82}$

\section{The nature of the clot and clot lysis time}

In many ways, fibrinogen polymerisation following thrombin activation is a remarkable process (Fig. 7, redrawn below from ref. 208), initially involving the release of two fibrinopeptides that cause lateral and end-to-end interactions via 'knobs' and 'holes', ultimately strengthened via the inter-strand covalent cross-linkages introduced later by factor XIII. Our interest is focussed on what determines the sizes, and especially the diameter, of individual fibrin fibres, since these may be observed under the electron microscope (e.g. ref. 171, 294, 297, 345, 353-360 and see later), and indeed the optical microscope, ${ }^{361,362}$ directly. An individual fibrinogen molecule is an elongated coiled coil, with a length and diameter of approximately 45 and $5 \mathrm{~nm}$, respectively. ${ }^{363,364}$ However, the diameter of 'typical' healthy fibrin fibres is of the other of $80-90 \mathrm{~nm}^{296,365}$ or more (as in Fig. 8). Thus to create every element of a fibre's width, even at the lower 'normal' diameter, requires the self-organisation of some 260 fibres (given that the formula for close-packing circles of diameter $d$ to make, or fit into, a bigger circle of diameter $D$ is $\left.N=0.9069 \times D^{2} / d^{2}\right)$. Our interest here lies in the recognition that variation in the kinetics or accretion (rate) of individual fibrinogen molecules and proto-fibrils changes not only the amount of a clot but the nature, diameter and architecture of the fibres of which it is formed, with considerable functional consequences for the performance (and ease of removal) of the clot itself. Thus in stroke, for instance, the fibrin fibres have an average (modal) diameter of some $35 \mathrm{~nm},{ }^{296}$ i.e. less than one half of that of healthy fibrin, evidently involving less than one quarter of the fibrinogen molecules per unit length. It is obviously of interest

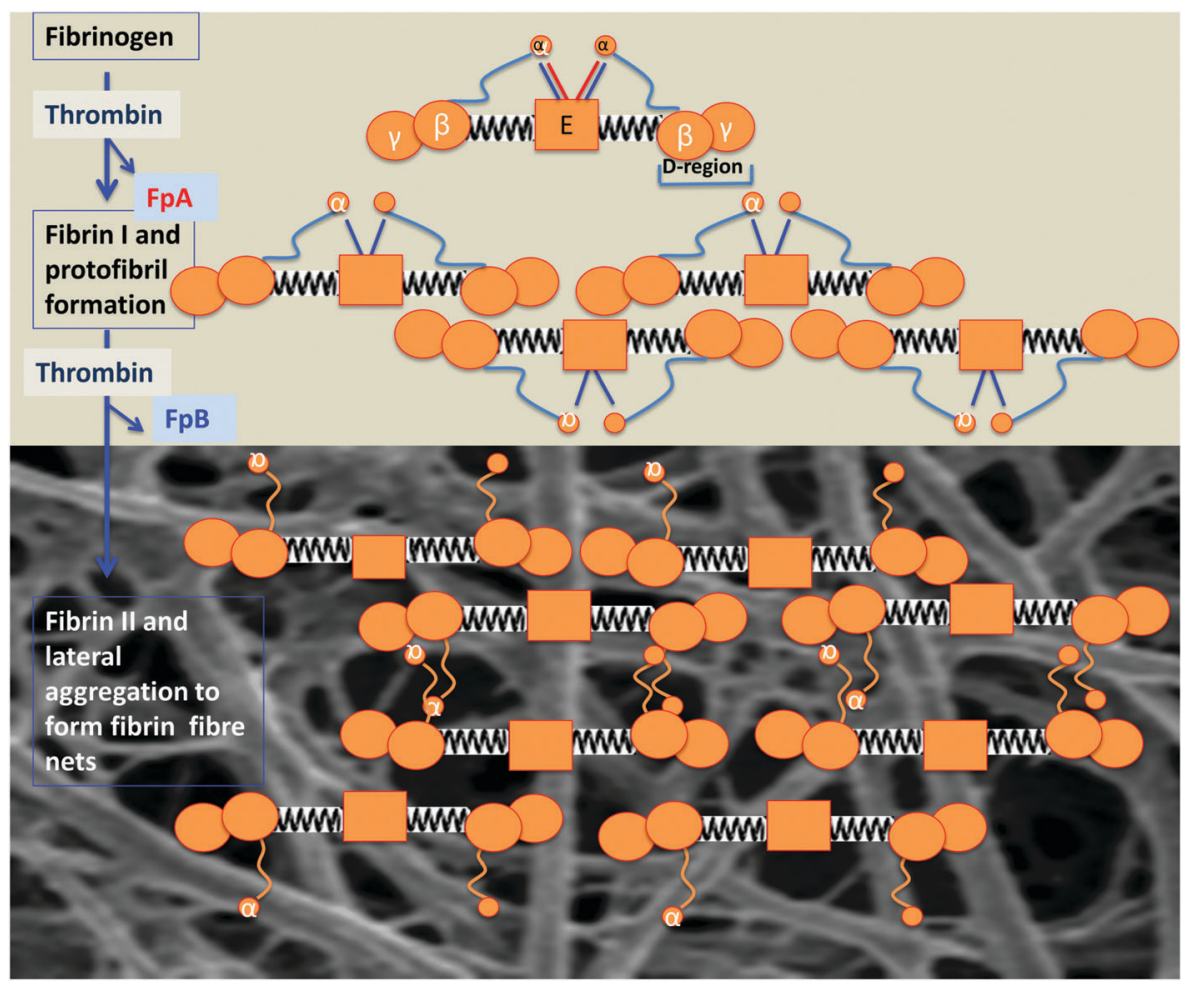

Fig. 7 Fibrinogen polymerisation following thrombin activation, indicating how the molecular structure of the fibrinogen changes and self-assembles to form macroscopic fibrin fibre nets, following the removal of fibrinopeptides $A$ and $B$ under the action of thrombin. Fibrinogen consists of $2 A \alpha, 2 B \beta$, and $2 \gamma$-chains, with a central E-region and D-regions, which are connected with an E-region by a coiled coil segment, composed of the $\beta$ - and $\gamma$-chain $\mathrm{C}$-termini; the $\alpha$-chain $\mathrm{C}$-termini fold back on the coiled coil and interact with the E-region. Fibrinopeptides $\mathrm{A}$ and $\mathrm{B}$ are released by the action of thrombin, and this initiates the polymerization of the fibrin protofibrils (redrawn from ref. 208). 

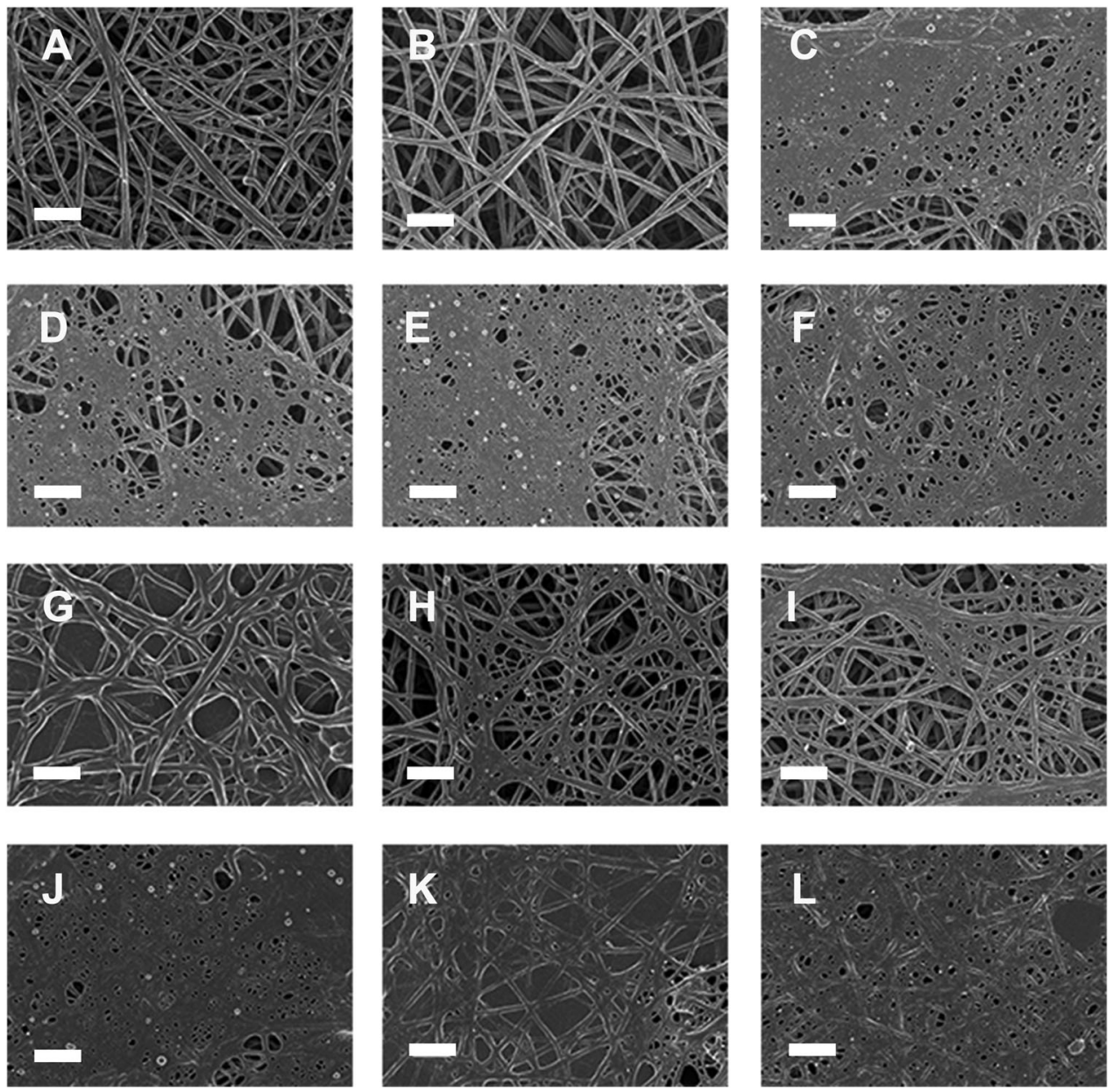

Fig. 8 Representative micrographs of platelet rich plasma (PRP) from 6 healthy individuals whose iron levels (iron, transferrin, \% saturation and serum ferritin) were within the healthy ranges. (A) PRP + thrombin; (B) PRP + thiourea + thrombin; (C) PRP + phytic acid + thrombin; (D) PRP + FeCl 3 + thrombin; (E) PRP + $\mathrm{AlCl}_{3}+$ thrombin; (F) PRP + $\mathrm{YCl}_{3}+$ thrombin; (G) PRP + $\mathrm{FeCl}_{3}+$ thiourea + thrombin; (H) PRP + $\mathrm{AlCl}_{3}+$ thiourea + thrombin; (I) PRP + YCl + thiourea + thrombin; (J) PRP + $\mathrm{FeCl}_{3}+$ phytic acid + thrombin; (K) PRP + $\mathrm{AlCl}_{3}+$ phytic acid + thrombin; and (L) PRP + $\mathrm{YCl} 3+$ phytic acid + thrombin. Scale bar $=1 \mu \mathrm{m}$. See also Table 5 and text.

to seek to understand what kinds of changes can effect such dramatic differences. In principle there can be at least three types: (i) changes in the amount of fibrinogen, (ii) changes in the amino acid sequence of fibrinogen, and (iii) changes in other substances in blood that interact with fibrinogen and affect its polymerisation. All three are known to occur.

\section{Effects of fibrinogen concentration on the nature of the clot}

Fibrinogen itself is a well-known inflammatory marker, and as inflammatory markers, fibrinogen levels are themselves of course also associated with a variety of diseases (see e.g. ref. 88, 366-376), and fibrin clot properties also vary in this way with various diseases (e.g. ref. 191 and 377). The nature of the clot structure also depends on a complex interplay of entropic and enthalpic mechanisms accompanying structural changes and that underpin the nonlinear mechanical response in fibrin networks undergoing compressive deformation. ${ }^{378}$
On simple kinetic grounds alone, changes in the fibrinogen concentration might be expected to have significant effects on the nature of the clot, and this is indeed observed, ${ }^{34,113,126,238,292,379}$ with, for instance, higher fibrinogen concentrations leading to faster clotting times and hence ${ }^{148}$ smaller clot pores. ${ }^{149,380,381}$

In addition to changes in fibrinogen levels, one might suppose that changes in the fibrinogen molecule itself would have substantial effects, and this too is found. In one very nice study, a common variant BßArg448Lys in the C-terminal region of the fibrinogen betachain had major effects on the nature of the clot, ${ }^{192}$ and the fact that this was also true for recombinant protein implied that the changes were due to interactions with substances in the blood itself.

\section{The role of iron ions and other substances in affecting fibrinogen and clot formation}

Fibrin(ogen) and clot formation is affected by a plethora of circulating plasma molecules, including collagen, fibronectin, 
Calcium ions bound both strongly and weakly to fibrin(ogen) have been localized, but this binding and interactions are only beginning to be discovered.

Fibrinogen/fibrin can bind to native collagen type I (Col I) and may use the Col I fiber network as a base to provide a functional interface matrix that connects cells to the Col I.

Fibroblast growth factor-2 (FGF-2) is a critical growth factor in normal and malignant cell proliferation and tumor-associated angiogenesis. Fibrinogen and fibrin bind to FGF-2 high affinity to fibrin(ogen) and modulate FGF-2 functions and this binding plays an important role in augmented angiogenesis.

Fibronectin may also affect clot properties, as it binds extracellular matrix components such as collagen and fibrin, and sometimes serves as a general cell adhesion molecule. Along with fibrin, plasma fibronectin is deposited at the site of injury, forming a blood clot that stops bleeding and protects the underlying tissue. An increase in fibronectin concentration results in thinner and denser fibers in the fibrin matrices as it is covalently and non-covalently bound to fibrin matrices.

Fibulins are a family of extracellular matrix and blood proteins presently having two members designated as fibulin-1 and -2 and fibulin- 1 can bind to fibrinogen; it was also found to be thrombi associated with human atherectomy specimens.

Similarly, the inflammatory mediator IL-1beta binds with high affinity to fibrin(ogen) and demonstrates increased activity in the bound form; and compared with free form, fibrinogen-bound IL-1beta stimulated increased activation of endothelial cell nuclear factor kappaB (NF-kappaB), monocyte chemo-attractant protein-1 (MCP-1) secretion, and nitric oxide (NO) synthesis.

There is also evidence that elevated lipoprotein(a) (Lp(a)) levels are associated with dense fibrin clots, reduced clot permeability and prolonged lysis time.

Low serum albumin was a modest marker of increased VTE risk.

Thrombospondins are proteins with antiangiogenic abilities and is a major platelet glycoprotein, which is released from platelets during blood coagulation and co-polymerizes with fibrin during blood coagulation and may be an important modulator of the clot structure.

von Willebrand factor-binding protein secreted by Staphylococcus aureus activates host prothrombin and form fibrin cables, thereby promoting the establishment of infectious lesions.

Zinc ions bind to the negatively charged fibrinogen, decrease thrombin's activity, but accelerate fibrin polymerisation, forming larger fibres.
$380,392,398$ and 399

386 and 387

388 and 390

400-402

383, 403-405 lipoprotein, albumin, thrombospondin, von Willebrand factor, fibulin, fibroblast growth factor-2, interleukin-1, and calcium, zinc and iron ions (see Table 4). ${ }^{382-395}$

A number of clot properties can vary under the influence of various molecules mentioned in the previous paragraph. These molecules may interact with fibrinogen and change the mechanical properties of clots, which are essential to the effective function of fibrin. Clot properties that may vary include the pore size, fibrin diameter, rigidity, ease of fibrinolysis, and so on ${ }^{208,396}$ (and some of these are correlated ${ }^{361,397}$ ).

Important to this review is that fibrinogen directly recognizes iron ion, the PPIX ring and metal ions complexed with the hemin (iron-protoporphyrin IX: PPIX) ring. ${ }^{389}$

\section{Electrostatic considerations}

The pI of fibrinogen is 5.5, i.e. it is negatively charged at neutral $\mathrm{pH}$ (as are the surfaces of erythrocytes). As one might expect, changes in ionic strength decrease the clot pore size. ${ }^{149,380,381}$ As one would also expect from Debye-Hückel theory, it binds divalent cations such as $\mathrm{Ca}^{2+380,392,398,399}$ and $\mathrm{Zn}^{2+404}$; the trivalent iron ion is especially effective. ${ }^{389,406}$ It has also been suggested that added ferric iron can carry out Fenton chemistry by reacting with peroxide that may be formed in a variety of ways. ${ }^{171,353,359,407,408}$ Thus both electrostatic phenomena and hydroxyl radical formation may modify the fibrinogen structure in such a way that its kinetics of polymerisation, and the structure of the fibrin products, is altered substantially.

\section{The action of phytic acid and thiourea in the presence of $\mathrm{Fe}^{3+}$, $\mathrm{Al}^{3+}$ and $\mathbf{Y}^{3+}$}

Phytic acid (myoinositol hexaphosphate) has 12 exchangeable protons, giving it a strong ability to complex with multivalent cations $^{409}$ (and indeed positively charged proteins). Trivalent ions are of special interest from an electrostatics point of view, and can be chosen to have very different chemistries and solvent interactions ${ }^{410}$ such that if their behaviour is similar it is likely their electrostatic rather than chemical properties that underpin this. ${ }^{411}$ Phytic acid, therefore, has the potential to remove metal ions such as $\mathrm{Fe}^{3+}, \mathrm{Al}^{3+}$ and $\mathrm{Y}^{3+}$ in the form of a metal-phytate complex, but not to serve as a hydroxyl radical trapper. ${ }^{412}$ By contrast, thiourea is not thought to be a metal chelator, but traps hydroxyl radicals (e.g. ref. 413). To this end, we studied the effects of these substances on fibrinogen polymerisation.

$\mathrm{AlCl}_{3}, \mathrm{FeCl}_{3}$ and $\mathrm{YCl}_{3}$ (final concentration $15 \mu \mathrm{M}$ ) were mixed with platelet rich plasma (PRP) from 6 healthy individuals prepared from blood drawn in citrate tubes. Full iron analysis showed that their basal iron levels (iron, serum ferritin transferrin and $\%$ saturation) were within the normal ranges as specified for 
Table 5 Sample preparation for and statistical analysis (to nearest $\mathrm{nm}$ ) of Fig. 8. Where present, final concentrations of $\mathrm{FeCl}_{3}, \mathrm{AlCl}_{3}$ and $\mathrm{YCl}_{3}$ were $15 \mu \mathrm{M}$, and of thiourea and phytic acid $30 \mu \mathrm{M}$

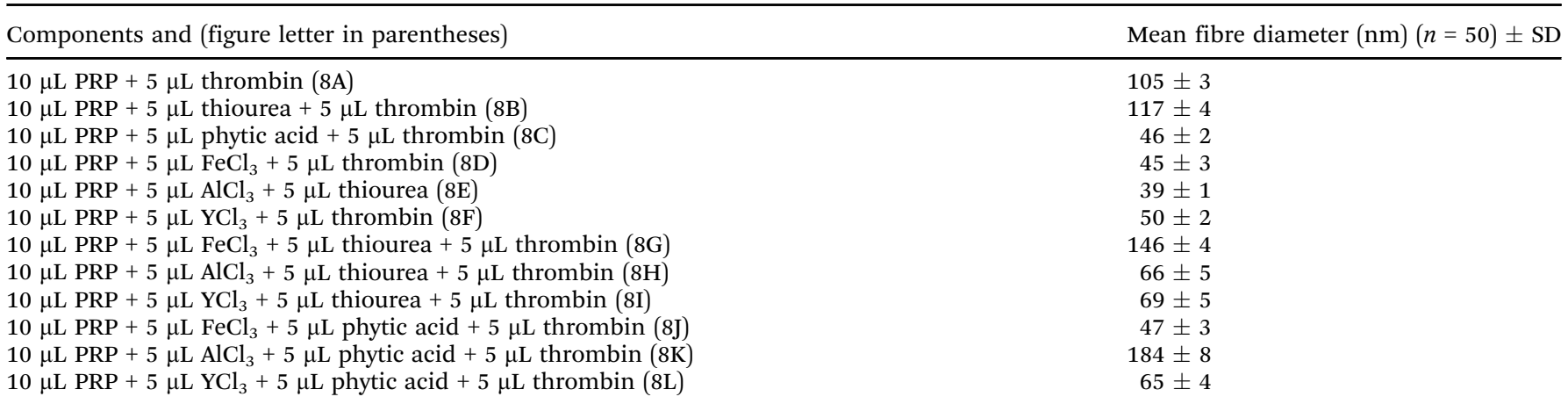

healthy individuals. Thrombin with and without either phytic acid or thiourea (final concentrations $30 \mu \mathrm{M}$ ) was added to PRP (pH: 7.38 (physiological pH)). See Table 5 for sample preparation and the mean diameter in $\mathrm{nm} \pm \mathrm{SD}$. Fibrin fibres were prepared for SEM according to methods published previously. ${ }^{359,360}$

SEM analysis of healthy fibrin fibre morphology (Fig. 8A) shows individual fibres that form a typical netlike structure. When thiourea is added to healthy PRP (Fig. 8B), no changes in fibrin fibre structure are noted; however, in the presence of phytic acid, instead of a healthy fibre structure, a dense netted layer (Fig. 8C) is formed. This netted appearance of the fibrin fibres was also noted with the addition of $\mathrm{FeCl}_{3}, \mathrm{AlCl}_{3}$ and $\mathrm{YCl}_{3}$ to healthy PRP (Fig. 8D to F) (final concentration of these substances in PRP was $15 \mu \mathrm{M}$ ), while the fibre diameters were approximately halved (as also seen in stroke ${ }^{296}$ ). When thiourea was added to a final concentration of $30 \mu \mathrm{M}$ to PRP and $\mathrm{FeCl}_{3}$, $\mathrm{AlCl}_{3}$ and $\mathrm{YCl}_{3}$, respectively (Fig. 8G to I), the fibrin structure was either protected or reverted back to a morphology more similar to that of healthy PRP. When phytic acid was added to a final concentration of $30 \mu \mathrm{M}$ to PRP and $\mathrm{FeCl}_{3}, \mathrm{AlCl}_{3}$ and $\mathrm{YCl}_{3}$, respectively, the fibrin structure changed to a thick, matted layer (Fig. 8J to L). This structure was denser than when only phytic acid was added to PRP (Fig. 8C) or when just $\mathrm{FeCl}_{3}, \mathrm{AlCl}_{3}$ or $\mathrm{YCl}_{3}$ were added to PRP (Fig. $8 \mathrm{D}$ to $\mathrm{F}$ ).

The above observations suggest that thiourea added to PRP does not have an electrostatic effect (as would indeed be expected in that it is uncharged). However, the addition of phytic acid to PRP (Fig. 8C) and $\mathrm{AlCl}_{3}$ (Fig. 8E) might suggest a purely electrostatic effect of both excessive cations and anions. The effects of PRP with $\mathrm{FeCl}_{3}$ and thiourea (Fig. 8G) could be interpreted as showing that at least in part the changes are due to $\mathrm{OH}^{\bullet}-$ but that is on the basis of thiourea not chelating. This suggests that the structural changes in the fibres that take place when $\mathrm{FeCl}_{3}$ is added to PRP and thrombin (Fig. 8D) might be contingent upon both an electrostatic (mainly) and an $\mathrm{OH}^{\bullet}$ (partly) effect.

Interestingly, it seems as if thiourea also stops the effect that $\mathrm{AlCl}_{3}\left(\mathrm{Al}^{3+}\right)$ has on the structure of the fibres (Fig. $\left.8 \mathrm{H}\right) \cdot \mathrm{Al}^{3+}$ does not on its own effect Fenton chemistry; however, under conditions where there might be iron present (as will be the case in PRP of healthy individuals) it can actually contribute to Fenton chemistry. ${ }^{414,415}$
Overall, these observations (and literature) are consistent with the view that a great many substances can have substantial effects on the rate of fibrinogen polymerisation and on the nature and structure of the fibres and clots formed. In some senses, fibrin structure might be considered to be a kind of bellwether of plasma health.

\section{Effects of non-ionic substances}

The nature of the clot formed upon thrombin activation can also be modulated by a variety of other substances ${ }^{416}$ besides trivalent ions. One such substance is glucose - and in diabetes the changes are more likely due to glycation of fibrinogen. ${ }^{236,416-418}$ Hormonal fluctuations also influence fibrin fibre morphology. Swanepoel and co-workers in 2014 were the first to show that oestrogen changes the ultrastructure of fibrin fibres. ${ }^{419,420}$ They found that the external and internal structure of the fibrin strands differed throughout the menstrual cycle. These changes coincided with the normal oestrogen peaks associated with the menstrual cycle. An increase in oestrogen during specifically the pre-ovulatory phase of the menstrual cycle resulted in a granular appearance of the fibrin network on high magnification. During pregnancy, which is associated with even more elevated oestrogen levels, the same granular appearance was typical, with an additional increase in dense matted deposits. These morphological changes persisted till at least 8 weeks post-partum. Oestrogen therefore may play a significant part in the hypercoagulable state associated with pregnancy.

The many oxidative and nitrosative stresses leading to protein modifications and their role in diseases are given e.g. by Dalle-Donne and colleagues. ${ }^{421-424}$ Unsurprisingly, substances that can react with fibrinogen directly can also have significant effects on clotting; indeed, aspirin affects the nature of the clot directly via acetylation, ${ }^{150}$ while peroxynitrite can inhibit fibrinolysis significantly, ${ }^{425}$ and fibrinogen nitration is pro-thrombotic. ${ }^{426,427}$

\section{Iron and blood storage}

Although not the entire focus of this article, we note that it is becoming increasingly recognised that as blood ages during storage it has a tendency to release iron and that this may give it properties that are suboptimal. ${ }^{428-438}$ As we have shown in the 
previous paragraphs, free iron can have a substantial role in determining the outcome of the clotting process, and this will need to be borne in mind as blood ages. The same is likely true for blood that ages in individuals. ${ }^{439,440}$

\section{Inflammation, fibrinogen and red cell aggregability as assessed via the erythrocyte sedimentation rate and other means}

As indicated, inflammation, fibrinogen levels and hypercoagulability are intimately connected. In a similar vein, fibrinogen levels are one of the strongest contributors to red cell aggregability and aggregation, ${ }^{441}$ and thence to the erythrocyte sedimentation rate, another classical indicator of inflammation. ${ }^{442-448}$ It should be noted that the difference between RBC aggregation and RBC aggregability is that the latter describes an intrinsic RBC property and the former describes the effect that results from this intrinsic cell property together with other factors (e.g. plasma proteins, temperature, $\mathrm{pH}$, shear rate, blood flow), resulting in RBC aggregation. In this regard it is accepted that fibrinogen increases RBC aggregation, not aggregability.

This can have a significant diagnostic and indeed prognostic value (e.g. ref. 449-454). Here, the Laser-Assisted Optical Rotational
Red Cell Analyzer (LORRCA) ${ }^{455-458}$ (marketed by Mechatronics) provides a convenient measurement, while atomic force microscopy assesses deformability at the level of the single cell. ${ }^{459-463}$

Similar comments apply to the changes in red cell distribution width also commonly seen in inflammatory diseases (e.g. ref. 464-474).

\section{Cytokines linking inflammation, hypercoagulability and hypofibrinolysis}

Given the considerable evidence noted above for the co-occurrence of inflammation, hypercoagulability and hypofibrinolysis, one might note in general terms that the relationship between two variables $\mathrm{A}$ and $\mathrm{B}$ that co-vary can take at least four forms: A affects B, $B$ affects $A$, both $A$ and $B$ affect each other, and D affects both $A$ and B. More complex variants such as A affects D and D affects $\mathrm{B}$ are not considered; these are known as 'indirect effects', and have proved problematic in studies of covariance (e.g. in protein folding based on phylogenetics, ${ }^{475}$ although considerable progress is being made in disentangling them ${ }^{476-480}$ ).

When looking for the potential biochemical changes or co-occurrences that might serve to link coagulation and inflammation, the chief players seem to be IL-1 $\beta^{481,482}$ and, in particular, IL-6, ${ }^{61,65,338,481-483}$ that seems to be involved in causing an

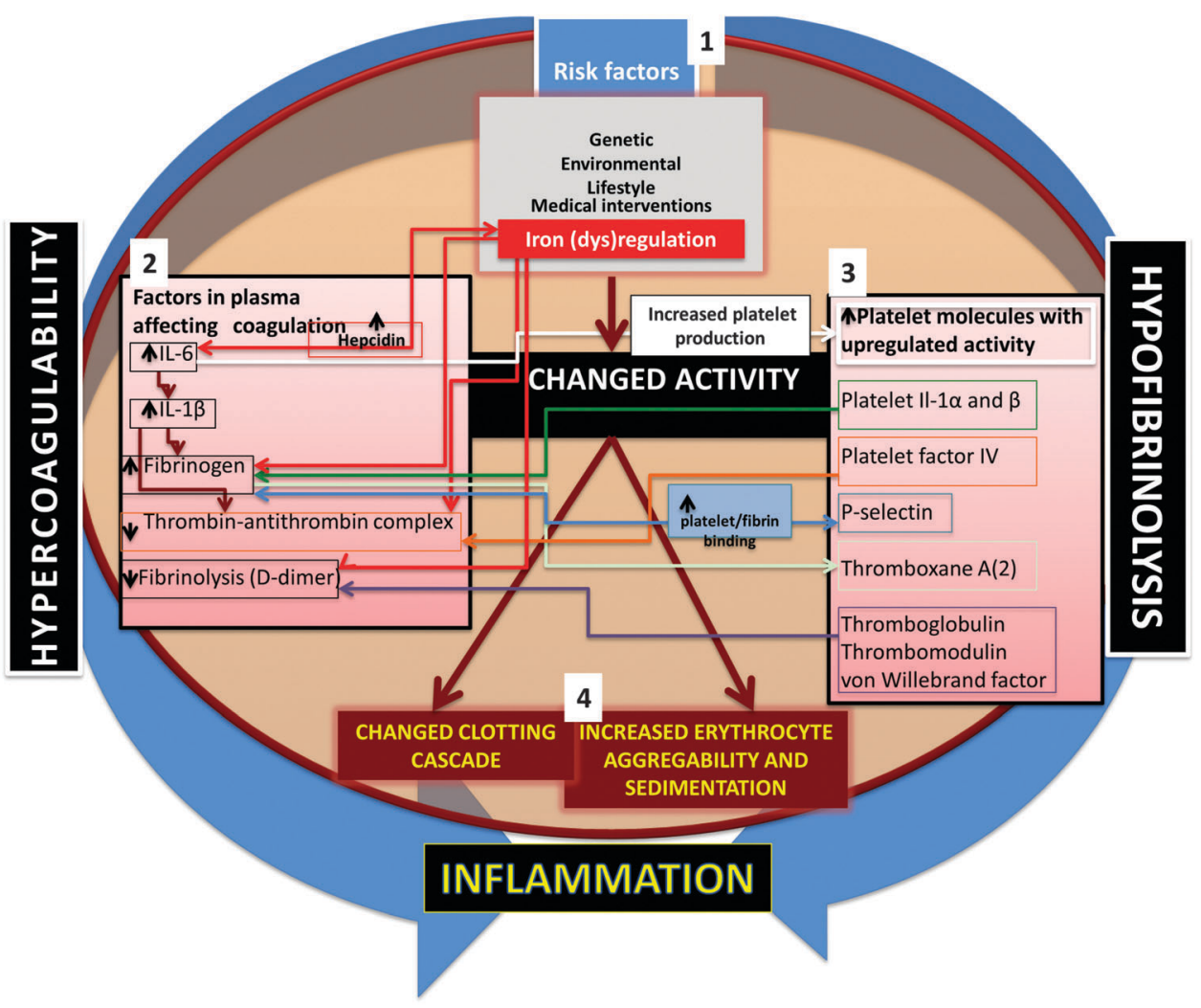

Fig. 9 Hypercoagulation, hypofibrinolysis and inflammation: a brief overview of the roles of plasma and platelet factors. Risk factors (1) cause a changed coagulation factor profile in plasma (2), as well as an upregulation activity of platelet products (3) which feeds back to affect each coagulation (indicated by arrows between 2 and 3). This results in a changed clotting profile and increased erythrocyte aggregability and sedimentation rate (4) that may be observed macroscopically. 
iterative cycle of coagulability and inflammation. One important mechanism involving the (IL-1-mediated) activation of IL-6 that in turn induces fibrinogen synthesis by hepatocytes ${ }^{484-486}$ and other cells ${ }^{482,487-490}$ is especially pertinent. IL-6 is also involved in iron (dys)regulation, in particular by its ability to induce hepcidin biosynthesis (e.g. ref. 491-499). An overview of the role of these cytokines is shown in Fig. 9.

\section{Relationship between inflammation and fibrosis}

Fibrosis refers to the laying down of pathological variants of a variety of proteins in an insoluble form, ${ }^{500}$ and also occurs in response to inflammation. Although we are concentrating here on events in blood, it is not a coincidence that 'fibrosis' shares the same etymological root as fibrin(oge)n. Most pertinently, fibrosis can be seen under the same hypercoagulable conditions as discussed here ${ }^{501-506}$ and may be considered to have a common cause (and, potentially, cure).

\section{Concluding remarks}

In the spirit of Integrative Biology, we have brought together a considerable body of literature on the effect that many diseases share a state of both hypercoagulability and hypofibrinolysis, and that part of this is due to the fact that they also share common causes in the form of inflammation and increased levels of substances such as inflammatory cytokines, fibrinogen and iron. Measuring these effects in blood or plasma may provide some useful and convenient approaches to diagnostics, and minimising them may provide some innovative system approaches to innovative therapies, to the benefit of all. Morphological methods cannot study changes or variations or conformational flexibility and variability of the specific forms (e.g. monomeric form) of the fibrin molecule, although this might indeed impact structural differences and polymerization characteristics. Therefore, ultrastructural investigation is proposed as a complementary methodology, together with methods described in this manuscript, to truly support an integrative approach to study clot formation (hypercoagulability) and hypofibrinolysis.

\section{Acknowledgements}

We thank the Biotechnology and Biological Sciences Research Council (BB/L025752/1) for supporting this collaboration. Janette Bester and Natasha Vermeulen prepared the samples for scanning electron microscopy.

\section{References}

1 M. Hoffman and D. M. Monroe, Coagulation 2006: a modern view of hemostasis, Hematol. Oncol. Clin. North Am., 2007, 21, 1-11.
2 M. R. Falvo, O. V. Gorkun and S. T. Lord, The molecular origins of the mechanical properties of fibrin, Biophys. Chem., 2010, 152, 15-20.

3 M. Delvaeye and E. M. Conway, Coagulation and innate immune responses: can we view them separately?, Blood, 2009, 114, 2367-2374.

4 S. Massberg, L. Grahl, M. L. von Bruehl, D. Manukyan, S. Pfeiler, C. Goosmann, V. Brinkmann, M. Lorenz, K. Bidzhekov, A. B. Khandagale, I. Konrad, E. Kennerknecht, K. Reges, S. Holdenrieder, S. Braun, C. Reinhardt, M. Spannagl, K. T. Preissner and B. Engelmann, Reciprocal coupling of coagulation and innate immunity via neutrophil serine proteases, Nat. Med., 2010, 16, 887-896.

5 C. T. Esmon, J. Xu and F. Lupu, Innate immunity and coagulation, J. Thromb. Haemostasis, 2011, 9, 182-188.

6 B. Engelmann and S. Massberg, Thrombosis as an intravascular effector of innate immunity, Nat. Rev. Immunol., 2013, 13, 34-45.

7 C. Schulz, B. Engelmann and S. Massberg, Crossroads of coagulation and innate immunity: the case of deep vein thrombosis, J. Thromb. Haemostasis, 2013, 11(suppl 1), 233-241.

8 F. Cacciapuoti, Some considerations about the hypercoagulable states and their treatments, Blood Coagulation Fibrinolysis, 2011, 22, 155-159.

9 N. Mackman, Triggers, targets and treatments for thrombosis, Nature, 2008, 451, 914-918.

10 A. G. G. Turpie and C. Esmon, Venous and arterial thrombosispathogenesis and the rationale for anticoagulation, Thromb. Haemostasis, 2011, 105, 586-596.

11 N. Mackman, New insights into the mechanisms of venous thrombosis, J. Clin. Invest., 2012, 122, 2331-2336.

12 F. Horsted, J. West and M. J. Grainge, Risk of venous thromboembolism in patients with cancer: a systematic review and meta-analysis, PLoS Med., 2012, 9, e1001275.

13 N. Mackman, Mouse models, risk factors, and treatments of venous thrombosis, Arterioscler., Thromb., Vasc. Biol., 2012, 32, 554-555.

14 Y. Zhang, S. Fan, Y. Yao, J. Ding, Y. Wang, Z. Zhao, L. Liao, P. Li, F. Zang and G. J. Teng, In vivo near-infrared imaging of fibrin deposition in thromboembolic stroke in mice, PLoS One, 2012, 7, e30262.

15 R. G. Hart, H. C. Diener, S. B. Coutts, J. D. Easton, C. B. Granger, M. J. O’Donnell, R. L. Sacco and S. J. Connolly, Embolic strokes of undetermined source: the case for a new clinical construct, Lancet Neurol., 2014, 13, 429-438.

16 C. Madias and R. G. Trohman, The link between atrial fibrillation and stroke in women, Women's Health, 2011, 7, 375-382.

17 N. N. Lang and D. T. Connelly, Novel oral anticoagulants for the prevention of thromboembolism in patients with atrial fibrillation, J. R. Coll. Physicians Edinb., 2013, 43, 151-158.

18 S. Ansar, E. Chatzikonstantinou, R. Thiagarajah, L. Tritschler, M. Fatar, M. G. Hennerici and S. Meairs, Pro-inflammatory mediators and apoptosis correlate to rt-PA response in a novel mouse model of thromboembolic stroke, PLoS One, 2014, 9, e85849. 
19 S. R. Levine, Hypercoagulable states and stroke: a selective review, CNS Spectr., 2005, 10, 567-578.

20 C. Medi, G. J. Hankey and S. B. Freedman, Stroke risk and antithrombotic strategies in atrial fibrillation, Stroke, 2010, 41, 2705-2713.

21 R. F. Franco and P. H. Reitsma, Genetic risk factors of venous thrombosis, Hum. Genet., 2001, 109, 369-384.

22 R. A. S. Ariëns, M. de Lange, H. Snieder, M. Boothby, T. D. Spector and P. J. Grant, Activation markers of coagulation and fibrinolysis in twins: heritability of the prethrombotic state, Lancet, 2002, 359, 667-671.

23 P. H. Viale, Abnormal clotting in cancer: an overview of pathophysiology and etiology, Semin. Oncol. Nurs., 2005, 21, 12-20.

24 I. Martinelli, Thromboembolism in women, Semin. Thromb. Hemostasis, 2006, 32, 709-715.

25 A. M. Carter, C. M. Cymbalista, T. D. Spector and P. J. Grant, Heritability of clot formation, morphology, and lysis: the EuroCLOT study, Arterioscler., Thromb., Vasc. Biol., 2007, 27, 2783-2789.

26 W. Tang, M. Teichert, D. I. Chasman, J. A. Heit, P. E. Morange, G. Li, N. Pankratz, F. W. Leebeek, G. Pare, M. de Andrade, C. Tzourio, B. M. Psaty, S. Basu, R. Ruiter, L. Rose, S. M. Armasu, T. Lumley, S. R. Heckbert, A. G. Uitterlinden, M. Lathrop, K. M. Rice, M. Cushman, A. Hofman, J. C. Lambert, N. L. Glazer, J. S. Pankow, J. C. Witteman, P. Amouyel, J. C. Bis, E. G. Bovill, X. Kong, R. P. Tracy, E. Boerwinkle, J. I. Rotter, D. A. Trégouët, D. W. Loth, B. H. Stricker, P. M. Ridker, A. R. Folsom and N. L. Smith, A genome-wide association study for venous thromboembolism: the extended cohorts for heart and aging research in genomic epidemiology (CHARGE) consortium, Genet. Epidemiol., 2013, 37, 512-521.

27 P. de Moerloose, A. Casini and M. Neerman-Arbez, Congenital Fibrinogen Disorders: An Update, Semin. Thromb. Hemostasis, 2013, 39, 585-595.

28 P. Woratanarat, C. Thaveeratitharm, T. Woratanarat, C. Angsanuntsukh, J. Attia and A. Thakkinstian, Metaanalysis of hypercoagulability genetic polymorphisms in Perthes disease, J. Orthop. Res., 2014, 32, 1-7.

29 M. Levi and S. M. Opal, Coagulation abnormalities in critically ill patients, Crit. Care, 2006, 10, 222.

30 P. Meybohm, K. Zacharowski and C. F. Weber, Point-ofcare coagulation management in intensive care medicine, Crit. Care, 2013, 17, 218.

31 F. Arshad, T. Lisman and R. J. Porte, Hypercoagulability as a contributor to thrombotic complications in the liver transplant recipient, Liver Int., 2013, 33, 820-827.

32 J. K. Hennigs, H. J. Baumann, N. Lüneburg, G. Quast, L. Harbaum, J. Heyckendorf, K. Sydow, B. Schulte-Hubbert, M. Halank and H. Klose, Fibrinogen plasma concentration is an independent marker of haemodynamic impairment in chronic thromboembolic pulmonary hypertension, Sci. Rep., 2014, 4, 4808.

33 C. M. Johnson, L. Mureebe and D. Silver, Hypercoagulable states: a review, Vasc. Endovascular Surg., 2005, 39, 123-133.
34 S. H. Alzahrani and R. A. Ajjan, Coagulation and fibrinolysis in diabetes, Diab. Vasc. Dis. Res., 2010, 7, 260-273.

35 J. A. M. Anderson and J. I. Weitz, Hypercoagulable states, Clin. Chest Med., 2010, 31, 659-673.

36 R. Houbballah and G. M. LaMuraglia, Clotting Problems: Diagnosis and Management of Underlying Coagulopathies, Semin. Vasc. Surg., 2010, 23, 221-227.

37 A. J. Chu, Tissue factor, blood coagulation, and beyond: an overview, Int. J. Inflammation, 2011, 2011, 367284.

38 P. H. Reitsma, H. H. Versteeg and S. Middeldorp, Mechanistic view of risk factors for venous thromboembolism, Arterioscler., Thromb., Vasc. Biol., 2012, 32, 563-568.

39 E. Klipp, R. Herwig, A. Kowald, C. Wierling and H. Lehrach, Systems biology in practice: concepts, implementation and clinical application, Wiley/VCH, Berlin, 2005.

$40 \mathrm{U}$. Alon, An introduction to systems biology: design principles of biological circuits, Chapman and Hall/CRC, London, 2006.

41 D. B. Kell and J. D. Knowles, The role of modeling in systems biology, in System modeling in cellular biology from concepts to nuts and bolts, ed. Z. Szallasi, J. Stelling and V. Periwal, MIT Press, Cambridge, 2006, pp. 3-18.

42 D. B. Kell, Metabolomics, modelling and machine learning in systems biology: towards an understanding of the languages of cells. The 2005 Theodor Bücher lecture, FEBS J., 2006, 273, 873-894.

43 В. $\emptyset$. Palsson, Systems biology: properties of reconstructed networks, Cambridge University Press, Cambridge, 2006.

44 E. H. S. Choy and G. S. Panayi, Mechanisms of disease: Cytokine pathways and joint inflammation in rheumatoid arthritis., N. Engl. J. Med., 2001, 344, 907-916.

$45 \mathrm{~W}$. W. Lin and M. Karin, A cytokine-mediated link between innate immunity, inflammation, and cancer, J. Clin. Invest., 2007, 117, 1175-1183.

46 M. Kopf, M. F. Bachmann and B. J. Marsland, Averting inflammation by targeting the cytokine environment, Nat. Rev. Drug Discovery, 2010, 9, 703-718.

47 C. Cicala and G. Cirino, Linkage between inflammation and coagulation: an update on the molecular basis of the crosstalk, Life Sci., 1998, 62, 1817-1824.

$48 \mathrm{M}$. Levi and $\mathrm{H}$. ten Cate, Disseminated intravascular coagulation, N. Engl. J. Med., 1999, 341, 586-592.

49 S. R. Coughlin, Thrombin signalling and proteaseactivated receptors, Nature, 2000, 407, 258-264.

50 P. Libby and D. I. Simon, Inflammation and thrombosis: the clot thickens, Circulation, 2001, 103, 1718-1720.

51 M. Thor, A. Yu and J. Swedenborg, Markers of inflammation and hypercoagulability in diabetic and nondiabetic patients with lower extremity ischemia, Thromb. Res., 2002, 105, 379-383.

52 D. S. G. Conway, P. Buggins, E. Hughes and G. Y. H. Lip, Predictive value of indexes of inflammation and hypercoagulability on success of cardioversion of persistent atrial fibrillation, Am. J. Cardiol., 2004, 94, 508-510.

53 M. Levi, T. van der Poll and H. R. Buller, Bidirectional relation between inflammation and coagulation, Circulation, 2004, 109, 2698-2704. 
54 M. Van de Wouwer, D. Collen and E. M. Conway, Thrombomodulin-protein C-EPCR system: integrated to regulate coagulation and inflammation, Arterioscler., Thromb., Vasc. Biol., 2004, 24, 1374-1383.

55 A. J. Chu, Tissue factor mediates inflammation, Arch. Biochem. Biophys., 2005, 440, 123-132.

56 P. Dusitanond, J. W. Eikelboom, G. J. Hankey, J. Thom, G. Gilmore, K. Loh, Q. Yi, C. J. M. Klijn, P. Langton, F. M. van Bockxmeer, R. Baker and K. Jamrozik, Homocysteine-lowering treatment with folic acid, cobalamin, and pyridoxine does not reduce blood markers of inflammation, endothelial dysfunction, or hypercoagulability in patients with previous transient ischemic attack or stroke: a randomized substudy of the VITATOPS trial, Stroke, 2005, 36, 144-146.

57 C. T. Esmon, The interactions between inflammation and coagulation, Br. J. Haematol., 2005, 131, 417-430.

58 A. Gupta, A. Watkins, P. Thomas, R. Majer, N. Habubi, G. Morris and K. Pansari, Coagulation and inflammatory markers in Alzheimer's and vascular dementia, Int. J. Clin. Pract., 2005, 59, 52-57.

59 O. A. Hatoum and D. G. Binion, The vasculature and inflammatory bowel disease: contribution to pathogenesis and clinical pathology, Inflammatory Bowel Dis., 2005, 11, 304-313.

60 G. Choi, M. J. Schultz, M. Levi and T. van der Poll, The relationship between inflammation and the coagulation system, Swiss Med. Wkly., 2006, 136, 139-144.

61 R. Marcucci, A. M. Gori, F. Giannotti, M. Baldi, V. Verdiani, S. Del Pace, C. Nozzoli and R. Abbate, Markers of hypercoagulability and inflammation predict mortality in patients with heart failure, J. Thromb. Haemostasis, 2006, 4, 1017-1022.

62 G. Aksu, C. Ozturk, K. Kavakli, F. Genel and N. Kutukculer, Hypercoagulability: interaction between inflammation and coagulation in familial Mediterranean fever, Clin. Rheumatol., 2007, 26, 366-370.

63 S. Anžej, M. Božič, A. Antovič, P. Peternel, N. Gašperšič, U. Rot, G. Tratar and M. Stegnar, Evidence of hypercoagulability and inflammation in young patients long after acute cerebral ischaemia, Thromb. Res., 2007, 120, 39-46.

$64 \mathrm{~K}$. Tomobe, The relation between adiponectin and four hypercoagulable, inflammatory biomarkers during normal pregnancy, Dokkyo J. Med. Sci., 2007, 34, 69-77.

65 E. Chertok-Shacham, A. Ishay, I. Lavi and R. Luboshitzky, Biomarkers of hypercoagulability and inflammation in primary hyperparathyroidism, Med. Sci. Monit., 2008, 14, CR628-CR632.

66 O. Karabudak, R. E. Ulusoy, A. A. Erikci, E. Solmazgul, B. Dogan and Y. Harmanyeri, Inflammation and hypercoagulable state in adult psoriatic men, Acta Derm.-Venereol., 2008, 88, 337-340.

67 Z. N. Kon, E. N. Brown, M. C. Grant, T. Ozeki, N. S. Burris, M. J. Collins, M. H. Kwon and R. S. Poston, Warm ischemia provokes inflammation and regional hypercoagulability within the heart during off-pump coronary artery bypass: a possible target for serine protease inhibition, Eur. J. Cardiothorac. Surg., 2008, 33, 215-221.

68 R. Medzhitov, Origin and physiological roles of inflammation, Nature, 2008, 454, 428-435.

69 P. A. Gurbel, K. P. Bliden, R. P. Kreutz, J. Dichiara, M. J. Antonino and U. S. Tantry, The link between heightened thrombogenicity and inflammation: pre-procedure characterization of the patient at high risk for recurrent events after stenting, Platelets, 2009, 20, 97-104.

70 H. Yoshida and D. N. Granger, Inflammatory Bowel Disease: A Paradigm for the Link Between Coagulation and Inflammation, Inflammatory Bowel Dis., 2009, 15, 1245-1255.

71 M. Levi and T. van der Poll, Inflammation and coagulation, Crit. Care Med., 2010, 38, S26-S34.

72 U. S. Tantry, K. P. Bliden, T. A. Suarez, R. P. Kreutz, J. Dichiara and P. A. Gurbel, Hypercoagulability, platelet function, inflammation and coronary artery disease acuity: results of the Thrombotic RIsk Progression (TRIP) study, Platelets, 2010, 21, 360-367.

73 J. I. Borissoff, H. M. H. Spronk and H. ten Cate, The Hemostatic System as a Modulator of Atherosclerosis, N. Engl. J. Med., 2011, 364, 1746-1760.

74 C. S. Kitchens, D. Erkan, L. R. Brandão, S. Hahn, A. H. James, R. Kulkarni, M. Pericak-Vance, J. Vance and T. L. Ortel, Thrombotic Storm Revisited: Preliminary Diagnostic Criteria Suggested by the Thrombotic Storm Study Group, Am. J. Med., 2011, 124, 290-296.

75 J. Petäjä, Inflammation and coagulation. An overview, Thromb. Res., 2011, 127(suppl 2), S34-S37.

76 T. van der Poll, J. D. de Boer and M. Levi, The effect of inflammation on coagulation and vice versa, Curr. Opin. Infect. Dis., 2011, 24, 273-278.

77 C. T. Esmon, Molecular circuits in thrombosis and inflammation, Thromb. Haemostasis, 2013, 109, 416-420.

78 M. Levi and T. van der Poll, Disseminated intravascular coagulation: a review for the internist, Intern. Emerg. Med., 2013, 8, 23-32.

79 C. T. Esmon, Targeting factor Xa and thrombin: impact on coagulation and beyond, Thromb. Haemostasis, 2014, 111, 625-633.

80 E. D. Weinberg, Iron out-of-balance: a risk factor for acute and chronic diseases, Hemoglobin, 2008, 32, 117-122.

81 D. B. Kell, Iron behaving badly: inappropriate iron chelation as a major contributor to the aetiology of vascular and other progressive inflammatory and degenerative diseases, BMC Med. Genomics, 2009, 2, 2.

82 D. B. Kell, Towards a unifying, systems biology understanding of large-scale cellular death and destruction caused by poorly liganded iron: Parkinson's, Huntington's, Alzheimer's, prions, bactericides, chemical toxicology and others as examples, Arch. Toxicol., 2010, 577, 825-889.

83 E. D. Weinberg, The hazards of iron loading, Metallomics, 2010, 2, 732-740.

84 T. D. Coates, Physiology and pathophysiology of iron in hemoglobin-associated diseases, Free Radical Biol. Med., 2014, 72C, 23-40. 
85 P. J. Urrutia, N. P. Mena and M. T. Núñez, The interplay between iron accumulation, mitochondrial dysfunction, and inflammation during the execution step of neurodegenerative disorders, Front. Pharmacol., 2014, 5, 38.

86 L. A. Norris, Blood coagulation, Best Pract. Res. Clin. Obstet. Gynaecol., 2003, 17, 369-383.

87 S. A. Smith, The cell-based model of coagulation, J. Vet. Emerg. Crit. Care, 2009, 19, 3-10.

88 E. Pretorius and D. B. Kell, Diagnostic morphology: biophysical indicators for iron-driven inflammatory diseases, Integr. Biol., 2014, 6, 486-510.

89 S. Narayanan, Multifunctional roles of thrombin, Ann. Clin. Lab. Sci., 1999, 29, 275-280.

90 S. S. Adam, N. S. Key and C. S. Greenberg, D-dimer antigen: current concepts and future prospects, Blood, 2009, 113, 2878-2887.

91 J. M. Siller-Matula, M. Schwameis, A. Blann, C. Mannhalter and B. Jilma, Thrombin as a multi-functional enzyme. Focus on in vitro and in vivo effects, Thromb. Haemostasis, 2011, 106, 1020-1033.

92 P. P. Tanos, G. K. Isbister, D. G. Lalloo, C. M. Kirkpatrick and S. B. Duffull, A model for venom-induced consumptive coagulopathy in snake bite, Toxicon, 2008, 52, 769-780.

93 T. Wajima, G. K. Isbister and S. B. Duffull, A comprehensive model for the humoral coagulation network in humans, Clin. Pharmacol. Ther., 2009, 86, 290-298.

94 A. Gulati, J. M. Faed, G. K. Isbister and S. B. Duffull, Development and evaluation of a prototype of a novel clotting time test to monitor enoxaparin, Pharm. Res., 2012, 29, 225-235.

95 A. Gulati, G. K. Isbister and S. B. Duffull, Effect of Australian elapid venoms on blood coagulation: Australian Snakebite Project (ASP-17), Toxicon, 2013, 61, 94-104.

96 A. Gulati, G. K. Isbister and S. B. Duffull, Scale reduction of a systems coagulation model with an application to modeling pharmacokinetic-pharmacodynamic data, CPT: Pharmacometrics Syst. Pharmacol., 2014, 3, e90.

97 N. Le Novère, B. Bornstein, A. Broicher, M. Courtot, M. Donizelli, H. Dharuri, L. Li, H. Sauro, M. Schilstra, B. Shapiro, J. L. Snoep and M. Hucka, BioModels Database: a free, centralized database of curated, published, quantitative kinetic models of biochemical and cellular systems, Nucleic Acids Res., 2006, 34, D689-D691.

98 C. Li, M. Donizelli, N. Rodriguez, H. Dharuri, L. Endler, V. Chelliah, L. Li, E. U. He, A. Henry, M. I. Stefan, J. L. Snoep, M. Hucka, N. Le Novère and C. Laibe, BioModels Database: An enhanced, curated and annotated resource for published quantitative kinetic models, BMC Syst. Biol., 2010, 4, 92.

99 C. Li, M. Courtot, N. Le Novère and C. Laibe, BioModels.net Web Services, a free and integrated toolkit for computational modelling software, Briefings Bioinf., 2010, 11, 270-277.

100 M. Hucka, A. Finney, H. M. Sauro, H. Bolouri, J. C. Doyle, H. Kitano, A. P. Arkin, B. J. Bornstein, D. Bray, A. CornishBowden, A. A. Cuellar, S. Dronov, E. D. Gilles, M. Ginkel,
V. Gor, I. I. Goryanin, W. J. Hedley, T. C. Hodgman, J. H. Hofmeyr, P. J. Hunter, N. S. Juty, J. L. Kasberger, A. Kremling, U. Kummer, N. Le Novere, L. M. Loew, D. Lucio, P. Mendes, E. Minch, E. D. Mjolsness, Y. Nakayama, M. R. Nelson, P. F. Nielsen, T. Sakurada, J. C. Schaff, B. E. Shapiro, T. S. Shimizu, H. D. Spence, J. Stelling, K. Takahashi, M. Tomita, J. Wagner and J. Wang, The systems biology markup language (SBML): a medium for representation and exchange of biochemical network models, Bioinformatics, 2003, 19, 524-531.

101 M. Hucka, A. Finney, B. J. Bornstein, S. M. Keating, B. E. Shapiro, J. Matthews, B. L. Kovitz, M. J. Schilstra, A. Funahashi, J. C. Doyle and H. Kitano, Evolving a lingua franca and associated software infrastructure for computational systems biology: the Systems Biology Markup Language (SBML) project, Syst. Biol., 2004, 1, 41-53.

102 M. Hoffman and D. M. Monroe, 3rd, A cell-based model of hemostasis, Thromb. Haemostasis, 2001, 85, 958-965.

103 D. M. Monroe and M. Hoffman, What does it take to make the perfect clot?, Arterioscler., Thromb., Vasc. Biol., 2006, 26, 41-48.

104 S. M. Bates and J. I. Weitz, Coagulation assays, Circulation, 2005, 112, e53-e60.

105 E. Berntorp and G. L. Salvagno, Standardization and clinical utility of thrombin-generation assays, Semin. Thromb. Hemostasis, 2008, 34, 670-682.

106 M. T. Ganter and C. K. Hofer, Coagulation monitoring: Current techniques and clinical use of viscoelastic point-ofcare coagulation devices, Anesth. Analg., 2008, 106, 1366-1375.

107 M. A. McMichael and S. A. Smith, Viscoelastic coagulation testing: technology, applications, and limitations, Vet. Clin. Pathol., 2011, 40, 140-153.

108 M. Chitlur, Challenges in the laboratory analyses of bleeding disorders, Thromb. Res., 2012, 130, 1-6.

109 P. I. Johansson, T. Stissing, L. Bochsen and S. R. Ostrowski, Thrombelastography and tromboelastometry in assessing coagulopathy in trauma, Scand. J. Trauma Resusc. Emerg. Med., 2009, 17, 45.

110 R. J. Luddington, Thrombelastography/thromboelastometry, Clin. Lab. Haematol., 2005, 27, 81-90.

111 H. Reikvam, E. Steien, B. Hauge, K. Liseth, K. G. Hagen, R. Storkson and T. Hervig, Thrombelastography, Transfus. Apher. Sci., 2009, 40, 119-123.

112 A. Afshari, A. Wikkelsø, J. Brok, A. M. Moller and J. Wetterslev, Thrombelastography (TEG) or thromboelastometry (ROTEM) to monitor haemotherapy versus usual care in patients with massive transfusion, Cochrane Database Syst. Rev., 2011, CD007871.

113 D. Bolliger, M. D. Seeberger and K. A. Tanaka, Principles and practice of thromboelastography in clinical coagulation management and transfusion practice, Transfus. Med. Rev., 2012, 26, 1-13.

114 A. Sankarankutty, B. Nascimento, L. Teodoro da Luz and S. Rizoli, TEG(R) and ROTEM(R) in trauma: similar test but different results?, World J. Emerg. Surg., 2012, 7(suppl 1), S3.

115 B. Sørensen and J. Ingerslev, Tailoring haemostatic treatment to patient requirements - an update on monitoring 
haemostatic response using thrombelastography, Haemophilia, 2005, 11(suppl 1), 1-6.

116 J. J. van Veen, A. Gatt, A. E. Bowyer, P. C. Cooper, S. Kitchen and M. Makris, Calibrated automated thrombin generation and modified thromboelastometry in haemophilia A, Thromb. Res., 2009, 123, 895-901.

117 U. Kjellberg and M. Hellgren, Sonoclot signature during normal pregnancy, Intensive Care Med., 2000, 26, 206-211.

118 D. A. Hett, D. Walker, S. N. Pilkington and D. C. Smith, Sonoclot analysis, Br. J. Anaesth., 1995, 75, 771-776.

119 S. Sharma, J. Uprichard, A. Moretti, H. Boyce, R. Szydlo and G. Stocks, Use of thromboelastography to assess the combined role of pregnancy and obesity on coagulation: a prospective study, Int. J. Obstet. Anesth., 2013, 22, 113-118.

120 M. Hellgren, Hemostasis during normal pregnancy and puerperium, Semin. Thromb. Hemostasis, 2003, 29, 125-130.

121 V. G. Nielsen, A comparison of the Thrombelastograph and the ROTEM, Blood Coagulation Fibrinolysis, 2007, 18, 247-252.

122 G. N. B. Jackson, K. J. Ashpole and S. M. Yentis, The $\operatorname{TEG}((\mathrm{R}))$ vs the ROTEM((R)) thromboelastography/thromboelastometry systems, Anaesthesia, 2009, 64, 212-215.

123 T. Tomori, D. Hupalo, K. Teranishi, S. Michaud, M. Hammett, D. Freilich, R. McCarron and F. Arnaud, Evaluation of coagulation stages of hemorrhaged swine: comparison of thromboelastography and rotational elastometry, Blood Coagulation Fibrinolysis, 2010, 21, 20-27.

124 L. F. Venema, W. J. Post, H. G. Hendriks, R. C. Huet, J. T. de Wolf and A. J. de Vries, An assessment of clinical interchangeability of TEG and ROTEM thromboelastographic variables in cardiac surgical patients, Anesth. Analg., 2010, 111, 339-344.

125 M. Furuhashi, N. Ura, K. Hasegawa, H. Yoshida, K. Tsuchihashi, T. Miura and K. Shimamoto, Sonoclot coagulation analysis: new bedside monitoring for determination of the appropriate heparin dose during haemodialysis, Nephrol., Dial., Transplant., 2002, 17, 1457-1462.

126 J. J. Liszka-Hackzell and G. Ekback, Analysis of the information content in Sonoclot data and reconstruction of coagulation test variables, J. Med. Syst., 2002, 26, 1-8.

127 T. Yamada, N. Katori, K. A. Tanaka and J. Takeda, Impact of Sonoclot hemostasis analysis after cardiopulmonary bypass on postoperative hemorrhage in cardiac surgery, J. Anesth., 2007, 21, 148-152.

128 K. R. Brandy, R. M. Meyer, X. Luo, G. H. Rao, Y. H. Datta and A. A. Divani, Evaluation of the coagulation profile among oral and vaginal combined hormonal contraceptive users using sonoclot coagulation analyzer, Clin. Appl. Thromb./Hemostasis, 2012, 18, 576-581.

129 V. G. Nielsen, B. M. Cohen and E. Cohen, Elastic modulusbased thrombelastographic quantification of plasma clot fibrinolysis with progressive plasminogen activation, Blood Coagulation Fibrinolysis, 2006, 17, 75-81.

130 V. G. Nielsen, Beyond cell based models of coagulation: analyses of coagulation with clot "lifespan" resistancetime relationships, Thromb. Res., 2008, 122, 145-152.
131 V. G. Nielsen, Corn trypsin inhibitor decreases tissue-type plasminogen activator-mediated fibrinolysis of human plasma, Blood Coagulation Fibrinolysis, 2009, 20, 191-196.

132 V. G. Nielsen, J. K. Kirklin, W. L. Holman and B. L. Steenwyk, Clot lifespan model analysis of the effects of warfarin on thrombus growth and fibrinolysis: role of contact protein and tissue factor initiation, ASAIO J., 2009, 55, 33-40.

133 V. G. Nielsen, R. T. Lyerly, 3rd and W. Q. Gurley, The effect of dilution on plasma coagulation kinetics determined by thrombelastography is dependent on antithrombin activity and mode of activation, Anesth. Analg., 2004, 99, 1587-1592, table of contents.

134 G. E. Rivard, K. E. Brummel-Ziedins, K. G. Mann, L. Fan, A. Hofer and E. Cohen, Evaluation of the profile of thrombin generation during the process of whole blood clotting as assessed by thrombelastography, J. Thromb. Haemostasis, 2005, 3, 2039-2043.

135 T. C. Ellis, V. G. Nielsen, M. B. Marques and J. K. Kirklin, Thrombelastographic measures of clot propagation: a comparison of alpha with the maximum rate of thrombus generation, Blood Coagulation Fibrinolysis, 2007, 18, 45-48.

136 T. M. Wilson, The conductivity of blood in coagulation, Biochem. J., 1907, 2, 377-382.

137 A. Ur, Changes in Electrical Impedance of Blood during Coagulation, Nature, 1970, 226, 269-270.

138 A. Ur, Detection of Clot Retraction through Changes of Electrical Impedance of Blood during Coagulation, Am. J. Clin. Pathol., 1971, 56, 713-718.

139 A. Ur, Analysis and Interpretation of Impedance BloodCoagulation Curve, Am. J. Clin. Pathol., 1977, 67, 470-476.

$140 \mathrm{H}$. Berney and J. J. O'Riordan, Impedance measurement monitors blood coagulation, Analog Dialogue, 2008, 42-08, 1-3.

141 Y. Hayashi, Y. Katsumoto, S. Omori, A. Yasuda, K. Asami, M. Kaibara and I. Uchimura, Dielectric coagulometry: a new approach to estimate venous thrombosis risk, Anal. Chem., 2010, 82, 9769-9774.

142 B. Ramaswamy, Y. T. T. Yeh and S. Y. Zheng, Microfluidic device and system for point-of-care blood coagulation measurement based on electrical impedance sensing, Sens. Actuators, B, 2013, 180, 21-27.

143 H. Beving, L. E. G. Eriksson, C. L. Davey and D. B. Kell, Dielectric properties of human blood and erythrocytes at radio frequencies $(0.2-10 \mathrm{MHz})$ : dependence on medium composition, Eur. Biophys. J., 1994, 23, 207-215.

144 R. Pethig and D. B. Kell, The passive electrical properties of biological systems: their significance in physiology, biophysics and biotechnology, Phys. Med. Biol., 1987, 32, 933-970.

145 C. M. Harris, R. W. Todd, S. J. Bungard, R. W. Lovitt, J. G. Morris and D. B. Kell, The dielectric permittivity of microbial suspensions at radio frequencies: a novel method for the estimation of microbial biomass, Enzyme Microb. Technol., 1987, 9, 181-186.

146 C. L. Davey, H. M. Davey, D. B. Kell and R. W. Todd, An Introduction to The Dielectric Estimation of Cellular 
Biomass in Real Time, with Special Emphasis on Measurements at High Volume Fractions, Anal. Chim. Acta, 1993, 279, 155-161.

147 C. L. Davey and D. B. Kell, The Low-Frequency Dielectric Properties of Biological Cells, in Bioelectrochemistry of Cells and Tissues, ed. D. Walz, H. Berg and G. Milazzo, Birkauser, Zürich, 1995, pp.159-207.

148 B. Blombäck and M. Okada, Fibrin gel structure and clotting time, Thromb. Res., 1982, 25, 51-70.

149 B. Blombäck, K. Carlsson, B. Hessel, A. Liljeborg, R. Procyk and N. Åslund, Native Fibrin Gel Networks Observed by 3d Microscopy, Permeation and Turbidity, Biochim. Biophys. Acta, 1989, 997, 96-110.

150 R. A. Ajjan, K. F. Standeven, M. Khanbhai, F. Phoenix, K. C. Gersh, J. W. Weisel, M. T. Kearney, R. A. S. Ariëns and P. J. Grant, Effects of aspirin on clot structure and fibrinolysis using a novel in vitro cellular system, Arterioscler., Thromb., Vasc. Biol., 2009, 29, 712-717.

151 E. Pretorius, S. Briedenhann, J. Marx, E. Smit, C. Van Der Merwe, M. Pieters and C. Franz, Ultrastructural comparison of the morphology of three different platelet and fibrin fiber preparations, Anat. Rec., 2007, 290, 188-198.

152 A. Undas, A. Slowik, P. Wolkow, A. Szczudlik and W. Tracz, Fibrin clot properties in acute ischemic stroke: relation to neurological deficit, Thromb. Res., 2010, 125, 357-361.

153 M. R. Martinez, A. Cuker, A. M. Mills, A. Crichlow, R. T. Lightfoot, I. N. Chernysh, C. Nagaswami, J. W. Weisel and H. Ischiropoulos, Enhanced lysis and accelerated establishment of viscoelastic properties of fibrin clots are associated with pulmonary embolism, Am. J. Physiol., 2014, 306, L397-L404.

154 M. M. Tripathi, Z. Hajjarian, E. M. Van Cott and S. K. Nadkarni, Assessing blood coagulation status with laser speckle rheology, Biomed. Opt. Express, 2014, 5, 817-831.

155 H. C. Chang, T. J. Cheng, T. H. Wu and T. M. Lin, Determination of coagulation time in whole blood containing anticoagulant by piezoelectric quartz crystal sensor, Sens. Actuators, B, 2000, 66, 296-298.

156 L. G. Puckett, G. Barrett, D. Kouzoudis, C. Grimes and L. G. Bachas, Monitoring blood coagulation with magnetoelastic sensors, Biosens. Bioelectron., 2003, 18, 675-681.

157 L. G. Puckett, J. K. Lewis, A. Urbas, X. D. Cui, D. Y. Gao and L. G. Bachas, Magnetoelastic transducers for monitoring coagulation, clot inhibition, and fibrinolysis, Biosens. Bioelectron., 2005, 20, 1737-1743.

158 T. M. Lin, T. J. Cheng, T. H. Wu and H. C. Chang, Comparing a piezoelectric quartz crystal with an optical coagulometer in monitoring high-dose heparin therapy by determining whole blood activated partial thromboplastin time and activated clotting time, Sens. Actuators, B, 2005, 109, 270-277.

159 L. F. Harris, V. Castro-Lopez and A. J. Killard, Coagulation monitoring devices: Past, present, and future at the point of care, TrAC, Trends Anal. Chem., 2013, 50, 85-95.

160 C. L. Yang, S. J. Huang, C. W. Chou, Y. C. Chiou, K. P. Lin, M. S. Tsai and K. C. Young, Design and evaluation of a portable optical-based biosensor for testing whole blood prothrombin time, Talanta, 2013, 116, 704-711.

161 C. Yao, L. Qu and W. Fu, Detection of fibrinogen and coagulation factor VIII in plasma by a quartz crystal microbalance biosensor, Sensors, 2013, 13, 6946-6956.

162 A. Undas, Fibrin clot properties and their modulation in thrombotic disorders, Thromb. Haemostasis, 2014, 112, 32-42.

163 E. Danese, M. Montagnana, G. Cervellin and G. Lippi, Hypercoagulability, D-dimer and atrial fibrillation: an overview of biological and clinical evidence, Ann. Med., 2014, 1-8.

164 A. Gupta and K. Pansari, The association between blood coagulation markers, atherothrombosis and dementia, Int. J. Clin. Pract., 2003, 57, 107-111.

165 L. Vaccarino, G. I. Forte, M. Palmeri, G. Misiano, E. Porcellini, M. Chiappelli, L. Scola, C. Caruso, F. Licastro and D. Lio, Role of prothrombotic polymorphisms in successful or unsuccessful aging, Biogerontology, 2011, 12, 445-450.

166 N. Purandare, A. Burns, K. J. Daly, J. Hardicre, J. Morris, G. Macfarlane and C. McCollum, Cerebral emboli as a potential cause of Alzheimer's disease and vascular dementia: case-control study, BMJ, 2006, 332, 1119-1122.

167 M. Cortes-Canteli and S. Strickland, Fibrinogen, a possible key player in Alzheimer's disease, J. Thromb. Haemostasis, 2009, 7, 146-150.

168 H. J. Ahn, D. Zamolodchikov, M. Cortes-Canteli, E. H. Norris, J. F. Glickman and S. Strickland, Alzheimer's disease peptide beta-amyloid interacts with fibrinogen and induces its oligomerization, Proc. Natl. Acad. Sci. U. S. A., 2010, 107, 21812-21817.

169 M. Cortes-Canteli, D. Zamolodchikov, H. J. Ahn, S. Strickland and E. H. Norris, Fibrinogen and Altered Hemostasis in Alzheimer's Disease, J. Alzheimer's Dis., 2012, 32, 599-608.

170 N. Purandare, A. Burns, J. Morris, E. P. Perry, J. Wren and C. McCollum, Association of Cerebral Emboli With Accelerated Cognitive Deterioration in Alzheimer's Disease and Vascular Dementia, Am. J. Psychiatry, 2012, 169, 300-308.

171 B. Lipinski and E. Pretorius, The Role of Iron-Induced Fibrin in the Pathogenesis of Alzheimer's Disease and the Protective Role of Magnesium, Front. Hum. Neurosci., 2013, 7, 735 .

172 J. L. Francis, D. A. Francis and G. J. Gunathilagan, Assessment of hypercoagulability in patients with cancer using the Sonoclot Analyzer and thromboelastography, Thromb. Res., 1994, 74, 335-346.

173 F. R. Rickles and M. N. Levine, Epidemiology of thrombosis in cancer, Acta Haematol., 2001, 106, 6-12.

174 F. R. Rickles and A. Falanga, Molecular basis for the relationship between thrombosis and cancer, Thromb. Res., 2001, 102, V215-V224.

175 G. J. Caine, P. S. Stonelake, G. Y. H. Lip and S. T. Kehoe, The hypercoagulable state of malignancy: pathogenesis and current debate, Neoplasia, 2002, 4, 465-473.

176 H. C. Kwaan, S. Parmar and J. Wang, Pathogenesis of increased risk of thrombosis in cancer, Semin. Thromb. Hemostasis, 2003, 29, 283-290. 
177 A. Y. Y. Lee and M. N. Levine, Venous thromboembolism and cancer: risks and outcomes, Circulation, 2003, 107, I17-I21.

178 R. S. Cunningham, Therapeutic options for the treatment of cancer-associated thrombosis, Semin. Oncol. Nurs., 2005, 21, 21-40.

179 P. K. Gupta, V. D. Charan and H. Kumar, Cancer related thrombophilia: clinical importance and management strategies, J. Assoc. Physicians India, 2005, 53, 877-882.

180 L. R. Zacharski, Hypercoagulability preceding cancer. The iron hypothesis, J. Thromb. Haemostasis, 2005, 3, 585-588.

181 F. R. Rickles, Cancer and thrombosis in women - molecular mechanisms, Thromb. Res., 2009, 123(suppl 2), S16-S20.

182 E. G. Aoun, K. M. Musallam, M. Abou-Ghazal and A. T. Taher, Malignancy and hypercoagulability: a two-way association revisited, J. Thromb. Thrombolysis, 2010, 30, 340-341.

183 L. G. Lima and R. Q. Monteiro, Activation of blood coagulation in cancer: implications for tumour progression, Biosci. Rep., 2013, 33, e00064.

184 A. Falanga, L. Russo and C. Verzeroli, Mechanisms of thrombosis in cancer, Thromb. Res., 2013, 131(suppl 1), S59-S62.

185 J. F. Timp, S. K. Braekkan, H. H. Versteeg and S. C. Cannegieter, Epidemiology of cancer-associated venous thrombosis, Blood, 2013, 122, 1712-1723.

186 E. D’Asti, N. Magnus, B. Meehan, D. Garnier and J. Rak, Genetic basis of thrombosis in cancer, Semin. Thromb. Hemostasis, 2014, 40, 284-295.

187 J. S. Chen, D. C. Chan, M. J. Chung, L. C. Chang and V. C. Yang, Altered fibrinolytic activities in gastric cancer and uremic patients after intervention, Clin. Nephrol., 2009, 72, 468-472.

188 C. J. Glueck, C. Richardson-Royer, R. Schultz, T. Burger, D. Bowe, J. Padda and P. Wang, Testosterone therapy, thrombophilia-hypofibrinolysis, and hospitalization for deep venous thrombosis-pulmonary embolus: an exploratory, hypothesis-generating study, Clin. Appl. Thromb./ Hemostasis, 2014, 20, 244-249.

189 S. Sallah, Review. Right ventricle thrombosis and the hypercoagulable states, Clin. Adv. Hematol. Oncol., 2004, 2,180 .

190 C. J. Song, A. Nakagomi, S. Chandar, H. Cai, I. G. S. Lim, H. P. McNeil, S. B. Freedman and C. L. Geczy, C-reactive protein contributes to the hypercoagulable state in coronary artery disease, J. Thromb. Haemostasis, 2006, 4, 98-106.

191 R. Ajjan and P. J. Grant, Coagulation and atherothrombotic disease, Atherosclerosis, 2006, 186, 240-259.

192 R. Ajjan, B. C. Lim, K. F. Standeven, R. Harrand, S. Dolling, F. Phoenix, R. Greaves, R. H. Abou-Saleh, S. Connell, D. A. Smith, J. W. Weisel, P. J. Grant and R. A. S. Ariëns, Common variation in the C-terminal region of the fibrinogen beta-chain: effects on fibrin structure, fibrinolysis and clot rigidity, Blood, 2008, 111, 643-650.

193 M. Y. Chan, F. Andreotti and R. C. Becker, Hypercoagulable states in cardiovascular disease, Circulation, 2008, 118, 2286-2297.
194 M. R. Di Tullio, S. Homma, Z. Jin and R. L. Sacco, Aortic atherosclerosis, hypercoagulability, and stroke the APRIS (Aortic Plaque and Risk of Ischemic Stroke) study, J. Am. Coll. Cardiol., 2008, 52, 855-861.

195 M. R. Di Tullio, C. Russo, Z. Z. Jin, R. L. Sacco, J. P. Mohr and S. Homma, P. F. O. C. S, Aortic Arch Plaques and Risk of Recurrent Stroke and Death, Circulation, 2009, 119, 2376-2382.

196 J. I. Borissoff, S. Heeneman, E. Kilinç, P. Kassák, R. Van Oerle, K. Winckers, J. W. P. Govers-Riemslag, K. Hamulyák, T. M. Hackeng, M. J. A. P. Daemen, H. Ten Cate and H. M. H. Spronk, Early Atherosclerosis Exhibits an Enhanced Procoagulant State, Circulation, 2010, 122, 821-830.

197 A. J. Yarur, A. R. Deshpande, D. M. Pechman, L. Tamariz, M. T. Abreu and D. A. Sussman, Inflammatory bowel disease is associated with an increased incidence of cardiovascular events, Am. J. Gastroenterol., 2011, 106, 741-747.

198 R. Loeffen, H. M. H. Spronk and H. ten Cate, The impact of blood coagulability on atherosclerosis and cardiovascular disease, J. Thromb. Haemostasis, 2012, 10, 1207-1216.

199 I. Juhan-Vague, M. C. Alessi and P. E. Morange, Hypofibrinolysis and increased PAI-1 are linked to atherothrombosis via insulin resistance and obesity, Ann. Med., 2000, 32(suppl 1), 78-84.

200 J. P. Collet, Y. Allali, C. Lesty, M. L. Tanguy, J. Silvain, A. Ankri, B. Blanchet, R. Dumaine, J. Gianetti, L. Payot, J. W. Weisel and G. Montalescot, Altered fibrin architecture is associated with hypofibrinolysis and premature coronary atherothrombosis, Arterioscler., Thromb., Vasc. Biol., 2006, 26, 2567-2573.

201 A. Undas, M. Celinska-Löwenhoff, T. Löwenhoff and A. Szczeklik, Statins, fenofibrate, and quinapril increase clot permeability and enhance fibrinolysis in patients with coronary artery disease, J. Thromb. Haemostasis, 2006, 4, 1029-1036.

202 A. Undas, D. Plicner, E. Stepien, R. Drwila and J. Sadowski, Altered fibrin clot structure in patients with advanced coronary artery disease: a role of C-reactive protein, lipoprotein(a) and homocysteine, J. Thromb. Haemostasis, 2007, 5, 1988-1990.

203 N. Bhasin, R. A. S. Ariëns, R. M. West, D. J. Parry, P. J. Grant and D. J. A. Scott, Altered fibrin clot structure and function in the healthy first-degree relatives of subjects with intermittent claudication, J. Vasc. Surg., 2008, 48, 1497-1503, 1503 e1491.

204 A. Undas, K. Szuldrzynski, E. Stepien, J. Zalewski, J. Godlewski, W. Tracz, M. Pasowicz and K. Zmudka, Reduced clot permeability and susceptibility to lysis in patients with acute coronary syndrome: effects of inflammation and oxidative stress, Atherosclerosis, 2008, 196, 551-557.

205 D. J. A. Scott, P. Prasad, H. Philippou, S. T. Rashid, S. Sohrabi, D. Whalley, A. Kordowicz, Q. Tang, R. M. West, A. Johnson, J. Woods, R. A. Ajjan and R. A. S. Ariëns, Clot architecture is altered in abdominal aortic aneurysms and correlates with aneurysm size, Arterioscler., Thromb., Vasc. Biol., 2011, 31, 3004-3010. 
206 M. Bochenek, J. Zalewski, J. Sadowski and A. Undas, Type 2 diabetes as a modifier of fibrin clot properties in patients with coronary artery disease, J. Thromb. Thrombolysis, 2013, 35, 264-270.

207 A. L. Cilia La Corte, H. Philippou and R. A. S. Ariëns, Role of fibrin structure in thrombosis and vascular disease, $A d v$. Protein Chem. Struct. Biol., 2011, 83, 75-127.

208 A. Undas and R. A. S. Ariëns, Fibrin clot structure and function: a role in the pathophysiology of arterial and venous thromboembolic diseases, Arterioscler., Thromb., Vasc. Biol., 2011, 31, e88-e99.

209 A. Undas, Acquired dysfibrinogenemia in atherosclerotic vascular disease, Pol. Arch. Med. Wewn., 2011, 121, 310-319.

210 Z. de Lange, M. Pieters, J. C. Jerling, A. Kruger and D. C. Rijken, Plasma clot lysis time and its association with cardiovascular risk factors in black Africans, PLOS One, 2012, 7, e48881.

211 R. A. S. Ariëns, Fibrin(ogen) and thrombotic disease, J. Thromb. Haemostasis, 2013, 11(suppl 1), 294-305.

212 C. Alessandri, S. Basili, F. Violi, P. Ferroni, P. P. Gazzaniga and C. Cordova, Hypercoagulability state in patients with chronic obstructive pulmonary disease. Chronic Obstructive Bronchitis and Haemostasis Group, Thromb. Haemostasis, 1994, 72, 343-346.

213 U. P. Kodavanti, M. C. Schladweiler, A. D. Ledbetter, R. V. Ortuno, M. Suffia, P. Evansky, J. H. Richards, R. H. Jaskot, R. Thomas, E. Karoly, Y. C. Huang, D. L. Costa, P. S. Gilmour and K. E. Pinkerton, The spontaneously hypertensive rat: an experimental model of sulfur dioxide-induced airways disease, Toxicol. Sci., 2006, 94, 193-205.

214 F. L. Fimognari, S. Scarlata, M. E. Conte and R. A. Incalzi, Mechanisms of atherothrombosis in chronic obstructive pulmonary disease, Int. J. Chronic Obstruct. Pulm. Dis., 2008, 3, 89-96.

215 A. Undas, P. Kaczmarek, K. Sladek, E. Stępień, W. Skucha, M. Rzeszutko, I. Gorkiewicz-Kot and W. Tracz, Fibrin clot properties are altered in patients with chronic obstructive pulmonary disease. Beneficial effects of simvastatin treatment, Thromb. Haemostasis, 2009, 102, 1176-1182.

216 C. Erem, I. Nuhoglu, M. Yilmaz, M. Kocak, A. Demirel, O. Ucuncu and H. O. Ersoz, Blood coagulation and fibrinolysis in patients with Cushing's syndrome: Increased plasminogen activator inhibitor-1, decreased tissue factor pathway inhibitor, and unchanged thrombin-activatable fibrinolysis inhibitor levels, J. Endocrinol. Invest., 2009, 32, 169-174.

217 B. Van Zaane, E. Nur, A. Squizzato, O. M. Dekkers, M. T. Twickler, E. Fliers, V. E. Gerdes, H. R. Buller and D. P. Brandjes, Hypercoagulable state in Cushing's syndrome: a systematic review, J. Clin. Endocrinol. Metab., 2009, 94, 2743-2750.

218 D. Kastelan, T. Dusek, I. Kraljevic, O. Polasek, Z. Giljevic, M. Solak, S. Z. Salek, J. Jelcic, I. Aganovic and M. Korsic, Hypercoagulability in Cushing's syndrome: the role of specific haemostatic and fibrinolytic markers, Endocrine, 2009, 36, 70-74.
219 L. Trementino, G. Arnaldi, G. Appolloni, V. Daidone, C. Scaroni, A. Casonato and M. Boscaro, Coagulopathy in Cushing's Syndrome, Neuroendocrinology, 2010, 92, 55-59.

220 R. van der Pas, C. de Bruin, F. W. Leebeek, M. P. de Maat, D. C. Rijken, A. M. Pereira, J. A. Romijn, R. T. Netea-Maier, A. R. Hermus, P. M. Zelissen, F. H. de Jong, A. J. van der Lely, W. W. de Herder, S. W. Lamberts, L. J. Hofland and R. A. Feelders, The hypercoagulable state in Cushing's disease is associated with increased levels of procoagulant factors and impaired fibrinolysis, but is not reversible after short-term biochemical remission induced by medical therapy, J. Clin. Endocrinol. Metab., 2012, 97, 1303-1310.

221 D. Kastelan, T. Dusek, I. Kraljevic and I. Aganovic, Hypercoagulable state in Cushing's syndrome is reversible following remission, Clin. Endocrinol., 2013, 78, 102-106.

222 R. van der Pas, F. W. G. Leebeek, L. J. Hofland, W. W. de Herder and R. A. Feelders, Hypercoagulability in Cushing's syndrome: prevalence, pathogenesis and treatment, Clin. Endocrinol., 2013, 78, 481-488.

223 J. H. Smalberg, M. J. Kruip, H. L. Janssen, D. C. Rijken, F. W. Leebeek and M. P. de Maat, Hypercoagulability and hypofibrinolysis and risk of deep vein thrombosis and splanchnic vein thrombosis: similarities and differences, Arterioscler., Thromb., Vasc. Biol., 2011, 31, 485-493.

224 C. J. Glueck, J. Friedman, A. Hafeez, A. Hassan and P. Wang, Testosterone, thrombophilia, thrombosis, Blood Coagulation Fibrinolysis, 2014, 25, 683-687.

225 G. Cesarman-Maus and K. A. Hajjar, Molecular mechanisms of fibrinolysis, Br. J. Haematol., 2005, 129, 307-321.

226 T. Lisman, P. G. de Groot, J. C. Meijers and F. R. Rosendaal, Reduced plasma fibrinolytic potential is a risk factor for venous thrombosis, Blood, 2005, 105, 1102-1105.

227 M. E. Carr, Diabetes mellitus: a hypercoagulable state, J. Diabetes Complications, 2001, 15, 44-54.

228 J. D. Banga, Coagulation and fibrinolysis in diabetes, Semin. Vasc. Med., 2002, 2, 75-86.

229 R. Aras, J. R. Sowers and R. Arora, The proinflammatory and hypercoagulable state of diabetes mellitus, Rev. Cardiovasc. Med., 2005, 6, 84-97.

230 P. J. Grant, Diabetes mellitus as a prothrombotic condition, J. Intern. Med., 2007, 262, 157-172.

231 A. Tripodi, A. Branchi, V. Chantarangkul, M. Clerici, G. Merati, A. Artoni and P. M. Mannucci, Hypercoagulability in patients with type 2 diabetes mellitus detected by a thrombin generation assay, J. Thromb. Thrombolysis, 2011, 31, 165-172.

232 Y. Ye, J. R. Perez-Polo, D. Aguilar and Y. Birnbaum, The potential effects of anti-diabetic medications on myocardial ischemia-reperfusion injury, Basic Res. Cardiol., 2011, 106, 925-952.

233 H. J. B. H. Beijers, I. Ferreira, H. M. H. Spronk, B. Bravenboer, J. M. Dekker, G. Nijpels, H. ten Cate and C. D. A. Stehouwer, Impaired glucose metabolism and type 2 diabetes are associated with hypercoagulability: potential role of central adiposity and low-grade inflammation--the Hoorn Study, Thromb. Res., 2012, 129, 557-562. 
234 M. Cucuianu, T. Fekete, C. Marcusiu, R. Mosler and A. Dutu, Fibrinolysis in diabetes mellitus. Role of overweight and hypertriglyceridemia, Med. Interne, 1984, 22, 171-177.

235 Y. Yano, N. Kitagawa, E. C. Gabazza, K. Morioka, H. Urakawa, T. Tanaka, A. Katsuki, R. Araki-Sasaki, Y. Hori, K. Nakatani, O. Taguchi, Y. Sumida and Y. Adachi, Increased plasma thrombin-activatable fibrinolysis inhibitor levels in normotensive type 2 diabetic patients with microalbuminuria, J. Clin. Endocrinol. Metab., 2003, 88, 736-741.

236 E. J. Dunn, R. A. S. Ariëns and P. J. Grant, The influence of type 2 diabetes on fibrin structure and function, Diabetologia, 2005, 48, 1198-1206.

237 E. J. Dunn, H. Philippou, R. A. S. Ariëns and P. J. Grant, Molecular mechanisms involved in the resistance of fibrin to clot lysis by plasmin in subjects with type 2 diabetes mellitus, Diabetologia, 2006, 49, 1071-1080.

238 S. H. Alzahrani, K. Hess, J. F. Price, M. Strachan, P. D. Baxter, R. Cubbon, F. Phoenix, T. Gamlen, R. A. S. Ariëns, P. J. Grant and R. A. Ajjan, Gender-specific alterations in fibrin structure function in type 2 diabetes: associations with cardiometabolic and vascular markers, J. Clin. Endocrinol. Metab., 2012, 97, E2282-E2287.

239 K. Hess, S. H. Alzahrani, M. Mathai, V. Schroeder, A. M. Carter, G. Howell, T. Koko, M. W. Strachan, J. F. Price, K. A. Smith, P. J. Grant and R. A. Ajjan, A novel mechanism for hypofibrinolysis in diabetes: the role of complement C3, Diabetologia, 2012, 55, 1103-1113.

240 M. Walus-Miarka, P. Wolkow, K. Cyganek, B. MirkiewiczSieradzka, M. T. Malecki and A. Undas, Altered fibrin-clot properties are associated with retinopathy in type 2 diabetes mellitus, Diabetes Metab., 2012, 38, 462-465.

241 M. Konieczynska, K. Fil, M. Bazanek and A. Undas, Prolonged duration of type 2 diabetes is associated with increased thrombin generation, prothrombotic fibrin clot phenotype and impaired fibrinolysis, Thromb. Haemostasis, 2014, 111, 685-693.

242 A. Nair, B. Sealove, J. L. Halperin, G. Webber and V. Fuster, Anticoagulation in patients with heart failure: who, when, and why?, Eur. Heart J. Suppl., 2006, 8, E32-E38.

243 A. Mongirdienè, L. Kuršvietienè and A. Kašauskas, The coagulation system changes in patients with chronic heart failure, Medicina, 2010, 46, 642-647.

244 V. G. Nielsen, J. K. Kirklin, W. L. Holman, B. L. Steenwyk, J. F. George, F. Zhou, D. A. Parks and T. C. Ellis, Mechanical circulatory device thrombosis: a new paradigm linking hypercoagulation and hypofibrinolysis, ASAIO J., 2008, 54, 351-358.

245 G. Twig, G. Zandman-Goddard, M. Szyper-Kravitz and Y. Shoenfeld, Systemic thromboembolism in inflammatory bowel disease: mechanisms and clinical applications, Ann. N. Y. Acad. Sci., 2005, 1051, 166-173.

246 S. Danese, A. Papa, S. Saibeni, A. Repici, A. Malesci and M. Vecchi, Inflammation and coagulation in inflammatory bowel disease: the clot thickens, Am. J. Gastroenterol., 2007, 102, 174-186.

247 H. Alkim, S. Ayaz, C. Alkim, A. Ulker and B. Sahin, Continuous active state of coagulation system in patients with nonthrombotic inflammatory bowel disease, Clin. Appl. Thromb./Hemostasis, 2011, 17, 600-604.

248 M. Lazzerini, M. Bramuzzo, M. Maschio, S. Martelossi and A. Ventura, Thromboembolism in Pediatric Inflammatory Bowel Disease: Systematic Review, Inflammatory Bowel Dis., 2011, 17, 2174-2183.

249 A. Deutschmann, A. Schlagenhauf, B. Leschnik, K. M. Hoffmann, A. Hauer and W. Muntean, Increased Procoagulant Function of Microparticles in Pediatric Inflammatory Bowel Disease: Role in Increased Thrombin Generation, J. Pediatr. Gastroenterol. Nutr., 2013, 56, 401-407.

250 C. M. Nylund, A. Goudie, J. M. Garza, G. Crouch and L. A. Denson, Venous thrombotic events in hospitalized children and adolescents with inflammatory bowel disease, J. Pediatr. Gastroenterol. Nutr., 2013, 56, 485-491.

251 D. Kohoutova, M. Pecka, M. Cihak, J. Cyrany, J. Maly and J. Bures, Prevalence of hypercoagulable disorders in inflammatory bowel disease, Scand. J. Gastroenterol., 2014, 49, 287-294.

252 D. Owczarek, D. Cibor, M. K. Glowacki, T. Rodacki and T. Mach, Inflammatory bowel disease: epidemiology, pathology and risk factors for hypercoagulability, World J. Gastroenterol., 2014, 20, 53-63.

253 J. C. Gris, J. F. Schved, C. Raffanel, A. Dubois, P. AguilarMartinez, A. Arnaud, N. Sanchez, C. Sarlat and J. L. Balmes, Impaired fibrinolytic capacity in patients with inflammatory bowel disease, Thromb. Haemostasis, 1990, 63, 472-475.

254 E. de Jong, R. J. Porte, E. A. Knot, J. H. Verheijen and J. Dees, Disturbed fibrinolysis in patients with inflammatory bowel disease. A study in blood plasma, colon mucosa, and faeces, Gut, 1989, 30, 188-194.

255 J. Shen, Z. H. Ran, Y. Zhang, Q. Cai, H. M. Yin, X. T. Zhou and S. D. Xiao, Biomarkers of altered coagulation and fibrinolysis as measures of disease activity in active inflammatory bowel disease: a gender-stratified, cohort analysis, Thromb. Res., 2009, 123, 604-611.

256 D. Owczarek, D. Cibor, K. Salapa, M. K. Glowacki, T. Mach and A. Undas, Reduced plasma fibrin clot permeability and susceptibility to lysis in patients with inflammatory bowel disease: a novel prothrombotic mechanism, Inflammatory Bowel Dis., 2013, 19, 2616-2624.

257 F. Dentali, E. Romualdi and W. Ageno, The metabolic syndrome and the risk of thrombosis, Haematologica, 2007, 92, 297-299.

258 M.-C. Alessi and I. Juhan-Vague, Metabolic syndrome, haemostasis and thrombosis, Thromb. Haemostasis, 2008, 99, 995-1000.

259 D. Vykoukal and M. G. Davies, Vascular biology of metabolic syndrome, J. Vasc. Surg., 2011, 54, 819-831.

260 F. Dentali, M. N. di Minno, M. Gianni, G. di Minno, A. Squizzato and W. Ageno, The role of the metabolic syndrome in patients with provoked venous thromboembolic events, Thromb. Haemostasis, 2013, 109, 759-761.

261 S. He, K. Bremme and M. Blomback, Acquired deficiency of antithrombin in association with a hypercoagulable state and impaired function of liver and/or kidney in 
preeclampsia, Blood Coagulation Fibrinolysis, 1997, 8, 232-238.

262 A. Kher, R. Bauersachs and J. D. Nielsen, The management of thrombosis in pregnancy: role of low-molecular-weight heparin, Thromb. Haemostasis, 2007, 97, 505-513.

263 A. S. Ducloy-Bouthors, Clotting disorders and preeclampsia (in French), Ann. Fr. Anesth. Reanim., 2010, 29, e121-e134.

264 L. M. Dusse, D. R. A. Rios, M. B. Pinheiro, A. J. Cooper and B. A. Lwaleed, Pre-eclampsia: relationship between coagulation, fibrinolysis and inflammation, Clin. Chim. Acta, 2011, 412, 17-21.

265 C. W. G. Redman, D. S. Tannetta, R. A. Dragovic, C. Gardiner, J. H. Southcombe, G. P. Collett and I. L. Sargent, Review: Does size matter? Placental debris and the pathophysiology of pre-eclampsia, Placenta, 2012, 33(suppl), S48-S54.

266 M. A. Martínez-Zamora, D. Tassies, F. Carmona, G. Espinosa, R. Cervera, J. C. Reverter and J. Balasch, Clot lysis time and thrombin activatable fibrinolysis inhibitor in severe preeclampsia with or without associated antiphospholipid antibodies, J. Reprod. Immunol., 2010, 86, 133-140.

267 C. J. Glueck, R. A. Freiberg, R. N. Fontaine, T. Tracy and P. Wang, Hypofibrinolysis, thrombophilia, osteonecrosis, Clin. Orthop. Relat. Res., 2001, 19-33.

268 A. P. Cellai, D. Lami, S. Fedi, R. Marcucci, L. Mannini, C. Cenci, A. Rogolino, A. Sodi, U. Menchini, R. Abbate and D. Prisco, A hypercoagulable and hypofibrinolytic state is detectable by global methods in patients with retinal vein occlusion, Atherosclerosis, 2012, 224, 97-101.

269 I. Karska-Basta, A. Kubicka-Trząska, B. RomanowskaDixon and A. Undas, Altered fibrin clot properties in patients with retinal vein occlusion, J. Thromb. Haemostasis, 2011, 9, 2513-2515.

270 Y. Mukubo and M. Kawamata, Perioperative hypercoagulability in patients with rheumatoid arthritis: Sonoclot study, J. Anesth., 2004, 18, 62-64.

271 Y. Shoenfeld, R. Gerli, A. Doria, E. Matsuura, M. M. Cerinic, N. Ronda, L. J. Jara, M. Abu-Shakra, P. L. Meroni and Y. Sherer, Accelerated atherosclerosis in autoimmune rheumatic diseases, Circulation, 2005, 112, 3337-3347.

272 R. J. Bisoendial, E. S. G. Stroes and P. P. Tak, Where the immune response meets the vessel wall, Neth. J. Med., 2009, 67, 328-333.

273 R. J. Bisoendial, M. Levi, P. P. Tak and E. S. G. Stroes, The prothrombotic state in rheumatoid arthritis: an additive risk factor for adverse cardiovascular events, Semin. Thromb. Hemostasis, 2010, 36, 452-457.

274 R. J. Bisoendial, E. S. G. Stroes, J. J. Kastelein and P. P. Tak, Targeting cardiovascular risk in rheumatoid arthritis: a dual role for statins, Nat. Rev. Rheumatol., 2010, 6, 157-164.

275 R. J. Bisoendial, E. S. G. Stroes and P. P. Tak, Critical determinants of cardiovascular risk in rheumatoid arthritis, Curr. Pharm. Des., 2011, 17, 21-26.

276 W. S. Chung, C. L. Peng, C. L. Lin, Y. J. Chang, Y. F. Chen, J. Y. Chiang, F. C. Sung and C. H. Kao, Rheumatoid arthritis increases the risk of deep vein thrombosis and pulmonary thromboembolism: a nationwide cohort study, Ann. Rheum. Dis., 2014, 73, 1774-1780.

277 J. F. Hesselvik, M. Blomback, B. Brodin and R. Maller, Coagulation, fibrinolysis, and kallikrein systems in sepsis: relation to outcome, Crit. Care Med., 1989, 17, 724-733.

278 G. R. Bernard, E. W. Ely, T. J. Wright, J. Fraiz, J. E. Stasek, Jr., J. A. Russell, I. Mayers, B. A. Rosenfeld, P. E. Morris, S. B. Yan and J. D. Helterbrand, Safety and dose relationship of recombinant human activated protein $\mathrm{C}$ for coagulopathy in severe sepsis, Crit. Care Med., 2001, 29, 2051-2059.

279 G. R. Bernard, J. L. Vincent, P. F. Laterre, S. P. LaRosa, J. F. Dhainaut, A. Lopez-Rodriguez, J. S. Steingrub, G. E. Garber, J. D. Helterbrand, E. W. Ely and C. J. Fisher, Jr., Efficacy and safety of recombinant human activated protein $\mathrm{C}$ for severe sepsis, N. Engl. J. Med., 2001, 344, 699-709.

280 M. A. Matthay, Severe sepsis--a new treatment with both anticoagulant and antiinflammatory properties, N. Engl. J. Med., 2001, 344, 759-762.

281 S. M. Opal and C. T. Esmon, Bench-to-bedside review: functional relationships between coagulation and the innate immune response and their respective roles in the pathogenesis of sepsis, Crit. Care, 2003, 7, 23-38.

282 S. Biswal and D. G. Remick, Sepsis: redox mechanisms and therapeutic opportunities, Antioxid. Redox Signaling, 2007, 9, 1959-1961.

283 D. G. Remick, Pathophysiology of sepsis, Am. J. Pathol., 2007, 170, 1435-1444.

284 R. J. Langley, E. L. Tsalik, J. C. van Velkinburgh, S. W. Glickman, B. J. Rice, C. Wang, B. Chen, L. Carin, A. Suarez, R. P. Mohney, D. H. Freeman, M. Wang, J. You, J. Wulff, J. W. Thompson, M. A. Moseley, S. Reisinger, B. T. Edmonds, B. Grinnell, D. R. Nelson, D. L. Dinwiddie, N. A. Miller, C. J. Saunders, S. S. Soden, A. J. Rogers, L. Gazourian, L. E. Fredenburgh, A. F. Massaro, R. M. Baron, A. M. Choi, G. R. Corey, G. S. Ginsburg, C. B. Cairns, R. M. Otero, V. G. Fowler, Jr., E. P. Rivers, C. W. Woods and S. F. Kingsmore, An integrated clinicometabolomic model improves prediction of death in sepsis, Sci. Transl. Med., 2013, 5, 195ra195.

285 A. P. Fletcher, N. Alkjaersig, A. Davies, M. Lewis, J. Brooks, W. Hardin, W. Landau and M. E. Raichle, Blood coagulation and plasma fibrinolytic enzyme system pathophysiology in stroke, Stroke, 1976, 7, 337-348.

286 G. Landi, A. D’Angelo, E. Boccardi, L. Candelise, P. M. Mannucci, E. Nobile Orazio and A. Morabito, Hypercoagulability in acute stroke: prognostic significance, Neurology, 1987, 37, 1667-1671.

287 K. Takano, T. Yamaguchi, Y. Okada, K. Uchida, W. Kisiel and H. Kato, Hypercoagulability in acute ischemic stroke: analysis of the extrinsic coagulation reactions in plasma by a highly sensitive automated method, Thromb. Res., 1990, 58, 481-491.

288 N. Matijevic and K. K. Wu, Hypercoagulable states and strokes, Curr. Atheroscler. Rep., 2006, 8, 324-329.

289 T. J. Bernard, L. Z. Fenton, S. D. Apkon, R. Boada, G. N. Wilkening, C. C. Wilkinson, J. B. Soep, S. D. Miyamoto, 
M. Tripputi, J. Armstrong-Wells, T. A. Benke, M. J. MancoJohnson and N. A. Goldenberg, Biomarkers of hypercoagulability and inflammation in childhood-onset arterial ischemic stroke, J. Pediatr., 2010, 156, 651-656.

290 K. L. Furie, S. E. Kasner, R. J. Adams, G. W. Albers, R. L. Bush, S. C. Fagan, J. L. Halperin, S. C. Johnston, I. Katzan, W. N. Kernan, P. H. Mitchell, B. Ovbiagele, Y. Y. Palesch, R. L. Sacco, L. H. Schwamm, S. WassertheilSmoller, T. N. Turan and D. Wentworth, Guidelines for the prevention of stroke in patients with stroke or transient ischemic attack: a guideline for healthcare professionals from the American heart association/American stroke association, Stroke, 2011, 42, 227-276.

291 P. Martínez-Sánchez, M. Martínez-Martínez, B. Fuentes, M. V. Cuesta, L. Cuéllar-Gamboa, L. Idrovo-Freire, J. Fernández-Dominguez and E. Diéz-Tejedor, Migraine and hypercoagulable states in ischemic stroke, Cephalalgia, 2011, 31, 1609-1617.

292 B. Kristensen, J. Malm, T. K. Nilsson, J. Hultdin, B. Carlberg and T. Olsson, Increased fibrinogen levels and acquired hypofibrinolysis in young adults with ischemic stroke, Stroke, 1998, 29, 2261-2267.

293 B. Kristensen, J. Malm, T. K. Nilsson, J. Hultdin, B. Carlberg, G. Dahlén and T. Olsson, Hyperhomocysteinemia and hypofibrinolysis in young adults with ischemic stroke, Stroke, 1999, 30, 974-980.

294 B. Lipinski, E. Pretorius, H. M. Oberholzer and W. J. Van Der Spuy, Iron enhances generation of fibrin fibers in human blood: Implications for pathogenesis of stroke, Microsc. Res. Tech., 2012, 75, 1185-1190.

295 B. Lipinski, E. Pretorius, H. M. Oberholzer and W. J. van der Spuy, Interaction of fibrin with red blood cells: the role of iron, Ultrastruct. Pathol., 2012, 36, 79-84.

296 E. Pretorius, H. Steyn, M. Engelbrecht, A. C. Swanepoel and H. M. Oberholzer, Differences in fibrin fiber diameters in healthy individuals and thromboembolic ischemic stroke patients, Blood Coagulation Fibrinolysis, 2011, 22, 696-700.

297 E. Pretorius and B. Lipinski, Differences in morphology of fibrin clots induced with thrombin and ferric ions and its pathophysiological consequences, Heart, Lung Circ., 2013, 22, 447-449.

298 E. Rooth, N. H. Wallen, M. Blomback and S. He, Decreased fibrin network permeability and impaired fibrinolysis in the acute and convalescent phase of ischemic stroke, Thromb. Res., 2011, 127, 51-56.

299 A. Undas, P. Podolec, K. Zawilska, M. Pieculewicz, I. Jedliński, E. Stępień, E. Konarska-Kuszewska, P. Weglarz, M. Duszynska, E. Hanschke, T. Przewlocki and W. Tracz, Altered fibrin clot structure/function in patients with cryptogenic ischemic stroke, Stroke, 2009, 40, 1499-1501.

300 S. M. Abo and V. A. DeBari, Laboratory evaluation of the antiphospholipid syndrome, Ann. Clin. Lab. Sci., 2007, 37, 3-14.

301 F. R. Dembitzer, M. R. Ledford Kraemer, P. Meijer and E. I. Peerschke, Lupus anticoagulant testing: performance and practices by North American clinical laboratories, Am. J. Clin. Pathol., 2010, 134, 764-773.
302 M. Jurado, J. A. Paramo, M. Gutierrez-Pimentel and E. Rocha, Fibrinolytic potential and antiphospholipid antibodies in systemic lupus erythematosus and other connective tissue disorders, Thromb. Haemostasis, 1992, 68, 516-520.

303 K. A. Krone, K. L. Allen and K. R. McCrae, Impaired fibrinolysis in the antiphospholipid syndrome, Curr. Rheumatol. Rep., 2010, 12, 53-57.

304 J. M. P. de Godoy, M. F. de Godoy and D. M. Braile, Recurrent thrombosis in patients with deep vein thrombosis and/or venous thromboembolism associated with anticardiolipin antibodies, Angiology, 2006, 57, 79-83.

305 J. A. Caprini, Risk assessment as a guide for the prevention of the many faces of venous thromboembolism, Am. J. Surg., 2010, 199, S3-S10.

306 M. Bern and N. McCarthy, Multiple markers of hypercoagulation in patients with history of venous thromboembolic disease, Blood Coagulation Fibrinolysis, 2013, 24, 59-63.

307 R. M. Van Haren, E. J. Valle, C. M. Thorson, J. M. Jouria, A. M. Busko, G. A. Guarch, N. Namias, A. S. Livingstone and K. G. Proctor, Hypercoagulability and other risk factors in trauma intensive care unit patients with venous thromboembolism, J. Trauma Acute Care Surg., 2014, 76, 443-449.

308 M. M. Aleman, B. L. Walton, J. R. Byrnes and A. S. Wolberg, Fibrinogen and red blood cells in venous thrombosis, Thromb. Res., 2014, 133(suppl 1), S38-S40.

309 J. Skov, J. J. Sidelmann, E. M. Bladbjerg, J. Jespersen and J. Gram, Difference in fibrinolytic capacity in young patients with venous thrombosis or ischaemic stroke, Blood Coagulation Fibrinolysis, 2014, 25, 61-66.

310 H. Watanabe, I. Kikkawa, S. Madoiwa, H. Sekiya, S. Hayasaka and Y. Sakata, Changes in blood coagulationfibrinolysis markers by pneumatic tourniquet during total knee joint arthroplasty with venous thromboembolism, J. Arthroplasty, 2014, 29, 569-573.

311 M. S. Siket and J. Edlow, Transient ischemic attack: an evidence-based update, Emerg. Med. Pract., 2013, 15, 1-26.

312 D. J. Dries, Activation of the clotting system and complement after trauma, New Horiz., 1996, 4, 276-288.

313 D. T. Engelman, S. G. Gabram, L. Allen, G. E. Ens and L. M. Jacobs, Hypercoagulability following multiple trauma, World J. Surg., 1996, 20, 5-10.

314 J. R. Hess, K. Brohi, R. P. Dutton, C. J. Hauser, J. B. Holcomb, Y. Kluger, K. Mackway-Jones, M. J. Parr, S. B. Rizoli, T. Yukioka, D. B. Hoyt and B. Bouillon, The coagulopathy of trauma: a review of mechanisms, J. Trauma, 2008, 65, 748-754.

315 R. Selby, W. Geerts, F. A. Ofosu, S. Craven, L. Dewar, A. Phillips and J. P. Szalai, Hypercoagulability after trauma: hemostatic changes and relationship to venous thromboembolism, Thromb. Res., 2009, 124, 281-287.

316 J. A. Differding, S. J. Underwood, P. Y. Van, R. A. Khaki, N. J. Spoerke and M. A. Schreiber, Trauma induces a hypercoagulable state that is resistant to hypothermia as measured by thrombelastogram, Am. J. Surg., 2011, 201, 587-591. 
317 C. T. Esmon and N. L. Esmon, The link between vascular features and thrombosis, Annu. Rev. Physiol., 2011, 73, 503-514.

318 M. S. Park, B. A. Owen, B. A. Ballinger, M. G. Sarr, H. J. Schiller, S. P. Zietlow, D. H. Jenkins, M. H. Ereth, W. G. Owen and J. A. Heit, Quantification of hypercoagulable state after blunt trauma: microparticle and thrombin generation are increased relative to injury severity, while standard markers are not, Surgery, 2012, 151, 831-836.

319 B. C. Branco, K. Inaba, C. Ives, O. Okoye, I. Shulman, J. S. David, H. Schöchl, P. Rhee and D. Demetriades, Thromboelastogram evaluation of the impact of hypercoagulability in trauma patients, Shock, 2014, 41, 200-207.

320 D. N. Kapsch, M. Metzler, M. Harrington, F. L. Mitchell and D. Silver, Fibrinolytic response to trauma, Surgery, 1984, 95, 473-478.

321 C. Kluft, J. H. Verheijen, A. F. Jie, D. C. Rijken, F. E. Preston, H. M. Sue-Ling, J. Jespersen and A. O. Aasen, The postoperative fibrinolytic shutdown: a rapidly reverting acute phase pattern for the fast-acting inhibitor of tissue-type plasminogen activator after trauma, Scand. J. Clin. Lab. Invest., 1985, 45, 605-610.

322 B. L. Enderson, J. P. Chen, R. Robinson and K. I. Maull, Fibrinolysis in multisystem trauma patients, J. Trauma, 1991, 31, 1240-1246.

323 M. D. Cappellini, L. Robbiolo, B. M. Bottasso, R. Coppola, G. Fiorelli and A. P. Mannucci, Venous thromboembolism and hypercoagulability in splenectomized patients with thalassaemia intermedia, Br. J. Haematol., 2000, 111, 467-473.

324 A. Eldor and E. A. Rachmilewitz, The hypercoagulable state in thalassemia, Blood, 2002, 99, 36-43.

325 K. I. Ataga, M. D. Cappellini and E. A. Rachmilewitz, Betathalassaemia and sickle cell anaemia as paradigms of hypercoagulability, Br. J. Haematol., 2007, 139, 3-13.

326 M. Bhattacharyya, M. Kannan, V. P. Chaudhry, M. Mahapatra, H. Pati and R. Saxena, Hypercoagulable state in five thalassemia intermedia patients, Clin. Appl. Thromb./Hemostasis, 2007, 13, 422-427.

327 A. T. Taher, Z. K. Otrock, I. Uthman and M. D. Cappellini, Thalassemia and hypercoagulability, Blood Rev., 2008, 22, 283-292.

328 M. Karimi, H. Bagheri, F. Rastgu and E. A. Rachmilewitz, Magnetic resonance imaging to determine the incidence of brain ischaemia in patients with beta-thalassaemia intermedia, Thromb. Haemostasis, 2010, 103, 989-993.

329 A. T. Taher, K. M. Musallam and A. Inati, The hypercoagulable state in thalassemia intermedia, Hemoglobin, 2009, 33(suppl 1), S160-S169.

330 A. Tripodi, M. D. Cappellini, V. Chantarangkul, L. Padovan, M. R. Fasulo, A. Marcon and P. M. Mannucci, Hypercoagulability in splenectomized thalassemic patients detected by whole-blood thromboelastometry, but not by thrombin generation in platelet-poor plasma, Haematologica, 2009, 94, 1520-1527.

331 M. D. Cappellini, I. Motta, K. M. Musallam and A. T. Taher, Redefining thalassemia as a hypercoagulable state, Ann. N. Y. Acad. Sci., 2010, 1202, 231-236.
332 M. D. Cappellini, K. M. Musallam and A. T. Taher, Thalassaemia as a hypercoagulable state, Touch Briefings, 2011, 214-216.

333 M. D. Cappellini, E. Poggiali, A. T. Taher and K. M. Musallam, Hypercoagulability in beta-thalassemia: a status quo, Expert Rev. Hematol., 2012, 5, 505-511; quiz 512.

334 M. D. Cappellini, K. M. Musallam, E. Poggiali and A. T. Taher, Hypercoagulability in non-transfusion-dependent thalassemia, Blood Rev., 2012, 26(suppl 1), S20-S23.

335 S. Haghpanah and M. Karimi, Cerebral thrombosis in patients with beta-thalassemia: a systematic review, Blood Coagulation Fibrinolysis, 2012, 23, 212-217.

336 S. Kemahli, C. Gürman, Y. Eğin, Y. Yildirmak, T. Sipahi, Z. Uysal, N. Akar, S. Cin and A. Arcasoy, Hypercoagulability in children with thalassemia major, Clin. Appl. Thromb./ Hemostasis, 1997, 3, 129-132.

337 G. M. Mokhtar, R. M. Matter, H. Shawki and M. M. Abdel Aziz, Thrombin activatable fibrinolysis inhibitor (TAFI): relationship to hemostatic alteration in patients with beta-thalassemia, Pediatr. Hematol. Oncol., 2010, 27, 363-373.

338 M. Cugno, A. Tedeschi, C. Crosti and A. V. Marzano, Activation of blood coagulation in autoimmune skin disorders, Expert Rev. Clin. Immunol., 2009, 5, 605-613.

339 M. Cugno, A. Tedeschi, R. Asero, P. L. Meroni and A. V. Marzano, Skin autoimmunity and blood coagulation, Autoimmunity, 2010, 43, 189-194.

340 M. Gaeta, S. Castelvecchio, C. Ricci, P. Pigatto, G. Pellissero and R. Cappato, Role of psoriasis as independent predictor of cardiovascular disease: a meta-regression analysis, Int. J. Cardiol., 2013, 168, 2282-2288.

341 A. J. Paidhungat, D. S. Salgaonkar, S. T. Nabar, M. Y. Nadkar, V. I. Chari, D. P. Khatri and S. R. Prabhu, Effect of inhaled terbutaline on platelet activity in bronchial asthma, J. Assoc. Physicians India, 1994, 42, 113-115.

342 H. B. Pandit, C. R. Spillert and R. D. Shih, Determination of hypercoagulable state in acute bronchospasm, J. Am. Osteopath. Assoc., 1999, 99, 203-206.

343 M. J. Utell and M. W. Frampton, Acute health effects of ambient air pollution: the ultrafine particle hypothesis, J. Aerosol Med., 2000, 13, 355-359.

344 R. M. Laryushkina, A. I. Ryvkin, T. G. Glazova, Y. Linkova, A. T. G. Reshetova, E. O. Safronova, T. B. Sokolova and I. K. Tomilova, Role of disorders in coagulofibrinolythic link of blood clotting and role of dyslipidemia in persistent course of pediatric bronchial asthma, Pediatriya, 2003, 6, 22-26.

345 E. Pretorius and H. M. Oberholzer, Ultrastructural changes of platelets and fibrin networks in human asthma: a qualitative case study, Blood Coagulation Fibrinolysis, 2009, 20, 146-149.

346 W. Burke, P. D. Phatak and E. D. Weinberg, The Iron Disorders Institute guide to hemochromatosis, Cumberland House, Nashville, TN, 2001.

347 G. T. Kinasewitz, J. G. Zein, G. L. Lee, S. A. Nazir and F. B. Taylor, Jr., Prognostic value of a simple evolving 
disseminated intravascular coagulation score in patients with severe sepsis, Crit. Care Med., 2005, 33, 2214-2221.

348 M. N. O'Riordan and J. R. Higgins, Haemostasis in normal and abnormal pregnancy, Best Pract. Res. Clin. Obstet. Gynaecol., 2003, 17, 385-396.

349 E. H. Uchikova and I. I. Ledjev, Changes in haemostasis during normal pregnancy, Eur. J. Obstet. Gynecol. Reprod. Biol., 2005, 119, 185-188.

350 P. B. Szecsi, M. Jorgensen, A. Klajnbard, M. R. Andersen, N. P. Colov and S. Stender, Haemostatic reference intervals in pregnancy, Thromb. Haemostasis, 2010, 103, 718-727.

351 P. Thornton and J. Douglas, Coagulation in pregnancy, Best practice \& research, Clin. Obstet. Gynecol., 2010, 24, 339-352.

352 S. G. Deeks, R. Tracy and D. C. Douek, Systemic effects of inflammation on health during chronic HIV infection, Immunity, 2013, 39, 633-645.

353 B. Lipinski and E. Pretorius, Iron-induced fibrin in cardiovascular disease, Curr. Neurovasc. Res., 2013, 10, 269-274.

354 E. Pretorius, U. B. Windberger, H. M. Oberholzer and R. E. Auer, Comparative ultrastructure of fibrin networks of a dog after thrombotic ischaemic stroke, Onderstepoort J. Vet. Res., 2010, 77, E1-E4.

355 E. Pretorius, H. M. Oberholzer, W. J. van der Spuy and J. H. Meiring, The changed ultrastructure of fibrin networks during use of oral contraception and hormone replacement, J. Thromb. Thrombolysis, 2010, 30, 502-506.

356 E. Pretorius, The use of a desktop scanning electron microscope as a diagnostic tool in studying fibrin networks of thrombo-embolic ischemic stroke, Ultrastruct. Pathol., 2011, 35, 245-250.

357 E. Pretorius, H. M. Oberholzer, W. J. van der Spuy, A. C. Swanepoel and P. Soma, Qualitative scanning electron microscopy analysis of fibrin networks and platelet abnormalities in diabetes, Blood Coagulation Fibrinolysis, 2011, 22, 463-467.

358 E. Pretorius, J. Olivier, H. M. Oberholzer and W. J. Van der Spuy, Scanning electron microscopy investigation of fibrin networks after thermal injury, Onderstepoort J. Vet. Res., 2011, 78, 244.

359 E. Pretorius, N. Vermeulen, J. Bester, B. Lipinski and D. B. Kell, A novel method for assessing the role of iron and its functional chelation in fibrin fibril formation: the use of scanning electron microscopy, Toxicol. Mech. Methods, 2013, 23, 352-359.

360 E. Pretorius, J. Bester, N. Vermeulen, B. Lipinski, G. S. Gericke and D. B. Kell, Profound morphological changes in the erythrocytes and fibrin networks of patients with hemochromatosis or with hyperferritinemia, and their normalization by iron chelators and other agents, PLoS One, 2014, 9, e85271.

361 B. Blombäck, K. Carlsson, K. Fatah, B. Hessel and R. Procyk, Fibrin in human plasma: gel architectures governed by rate and nature of fibrinogen activation, Thromb. Res., 1994, 75, 521-538.

362 B. Blombäck and N. Bark, Fibrinopeptides and fibrin gel structure, Biophys. Chem., 2004, 112, 147-151.
363 J. H. Brown, N. Volkmann, G. Jun, A. H. Henschen-Edman and C. Cohen, The crystal structure of modified bovine fibrinogen, Proc. Natl. Acad. Sci. U. S. A., 2000, 97, 85-90.

364 M. W. Mosesson, Fibrinogen and fibrin structure and functions, J. Thromb. Haemostasis, 2005, 3, 1894-1904.

365 K. M. Weigandt, N. White, D. Chung, E. Ellingson, Y. Wang, X. Y. Fu and D. C. Pozzo, Fibrin Clot Structure and Mechanics Associated with Specific Oxidation of Methionine Residues in Fibrinogen, Biophys. J., 2012, 103, 2399-2407.

366 J. Danesh, R. Collins, P. Appleby and R. Peto, Association of fibrinogen, C-reactive protein, albumin, or leukocyte count with coronary heart disease: meta-analyses of prospective studies, JAMA, J. Am. Med. Assoc., 1998, 279, 1477-1482.

367 N. Ossei-Gerning, I. J. Wilson and P. J. Grant, Sex differences in coagulation and fibrinolysis in subjects with coronary artery disease, Thromb. Haemostasis, 1998, 79, 736-740.

368 C. Bickel, H. J. Rupprecht, S. Blankenberg, C. Espiniola-Klein, A. Schlitt, G. Rippin, G. Hafner, R. Treude, H. Othman, K. P. Hofmann, J. Meyer and A. Investigators, Relation of markers of inflammation (C-reactive protein, fibrinogen, von Willebrand factor, and leukocyte count) and statin therapy to long-term mortality in patients with angiographically proven coronary artery disease, Am. J. Cardiol., 2002, 89, 901-908.

369 E. Réganon, V. Vila, V. Martínez-Sales, A. Vaya and J. Aznar, Inflammation, fibrinogen and thrombin generation in patients with previous myocardial infarction, Haematologica, 2002, 87, 740-745.

370 P. Jousilahti, V. Salomaa, V. Rasi, E. Vahtera and T. Palosuo, Association of markers of systemic inflammation, $\mathrm{C}$ reactive protein, serum amyloid A, and fibrinogen, with socioeconomic status, J. Epidemiol. Community Health, 2003, 57, 730-733.

371 C. Zoccali, F. A. Benedetto, F. Mallamaci, G. Tripepi, S. Cutrupi, S. Parlongo, L. S. Malatino, G. Bonanno, F. Rapisarda, P. Fatuzzo, G. Seminara, G. Nicocia and M. Buemi, Fibrinogen, inflammation and concentric left ventricular hypertrophy in chronic renal failure, Eur. J. Clin. Invest., 2003, 33, 561-566.

372 J. Danesh, S. Lewington, S. G. Thompson, G. D. O. Lowe, R. Collins and Fibrinogen Studies Collaboration, Plasma fibrinogen level and the risk of major cardiovascular diseases and nonvascular mortality - An individual participant meta-analysis, JAMA, J. Am. Med. Assoc., 2005, 294, 1799-1809.

373 D. Green, C. Chan, J. Kang, K. Liu, P. Schreiner, N. S. Jenny and R. P. Tracy, Longitudinal assessment of fibrinogen in relation to subclinical cardiovascular disease: the CARDIA study, J. Thromb. Haemostasis, 2010, 8, 489-495.

374 D. Zapryanova, L. Lazarov, T. M. Georgieva, J. Nikolov, N. Goranov, I. Dinev and I. Stoycheva, Markers of inflammation in experimentally induced pancreatitis in dogs (Part III): Blood plasma protein profiles and fibrinogen, Rev. Med. Vet., 2011, 162, 449-453.

375 D. Davalos and K. Akassoglou, Fibrinogen as a key regulator of inflammation in disease, Semin. Immunopathol., 2012, 34, 43-62. 
376 M. Swarowska, A. Janowska, A. Polczak, A. KlimkowiczMrowiec, J. Pera, A. Slowik and T. Dziedzic, The Sustained Increase of Plasma Fibrinogen During Ischemic Stroke Predicts Worse Outcome Independently of Baseline Fibrinogen Level, Inflammation, 2014, 37, 1142-1147.

377 G. Jörneskog, N. Egberg, B. Fagrell, K. Fatah, B. Hessel, H. Johnsson, K. Brismar and M. Blombäck, Altered properties of the fibrin gel structure in patients with IDDM, Diabetologia, 1996, 39, 1519-1523.

378 O. V. Kim, R. I. Litvinov, J. W. Weisel and M. S. Alber, Structural basis for the nonlinear mechanics of fibrin networks under compression, Biomaterials, 2014, 35, 6739-6749.

379 R. D. McBane, R. M. Hardison, 2nd and B. E. Sobel, Comparison of plasminogen activator inhibitor-1, tissue type plasminogen activator antigen, fibrinogen, and D-dimer levels in various age decades in patients with type 2 diabetes mellitus and stable coronary artery disease (from the BARI 2D trial), Am. J. Cardiol., 2010, 105, 17-24.

380 M. Okada and B. Blombäck, Calcium and fibrin gel structure, Thromb. Res., 1983, 29, 269-280.

381 M. Okada and B. Blomback, Factors influencing fibrin gel structure studied by flow measurement, Ann. N. Y. Acad. Sci., 1983, 408, 233-253.

382 H. Tran, A. Tanaka, S. V. Litvinovich, L. V. Medved, C. C. Haudenschild and W. S. Argraves, The interaction of fibulin-1 with fibrinogen. A potential role in hemostasis and thrombosis, J. Biol. Chem., 1995, 270, 19458-19464.

383 G. Marx, Zinc binding to fibrinogen and fibrin, Arch. Biochem. Biophys., 1988, 266, 285-288.

384 A. Sahni, M. Guo, S. K. Sahni and C. W. Francis, Interleukin-1beta but not IL-1alpha binds to fibrinogen and fibrin and has enhanced activity in the bound form, Blood, 2004, 104, 409-414.

385 J. W. Weisel, Fibrinogen and fibrin, Adv. Protein Chem., 2005, 70, 247-299.

386 A. Sahni, A. A. Khorana, R. B. Baggs, H. Peng and C. W. Francis, FGF-2 binding to fibrin(ogen) is required for augmented angiogenesis, Blood, 2006, 107, 126-131.

387 A. Sahni, P. J. Simpson-Haidaris, S. K. Sahni, G. G. Vaday and C. W. Francis, Fibrinogen synthesized by cancer cells augments the proliferative effect of fibroblast growth factor-2 (FGF-2), J. Thromb. Haemostasis, 2008, 6, 176-183.

388 A. R. Folsom, P. L. Lutsey, S. R. Heckbert and M. Cushman, Serum albumin and risk of venous thromboembolism, Thromb. Haemostasis, 2010, 104, 100-104.

389 K. Orino, Functional binding analysis of human fibrinogen as an iron- and heme-binding protein, BioMetals, 2013, 26, 789-794.

390 E. Pretorius, B. Lipinski, J. Bester, N. Vermeulen and P. Soma, Albumin stabilizes fibrin fiber ultrastructure in low serum albumin type 2 diabetes, Ultrastruct. Pathol., 2013, 37, 254-257.

391 L. Thomer, O. Schneewind and D. Missiakas, Multiple ligands of von Willebrand factor-binding protein (vWbp) promote Staphylococcus aureus clot formation in human plasma, J. Biol. Chem., 2013, 288, 28283-28292.
392 J. W. Weisel and R. I. Litvinov, Mechanisms of fibrin polymerization and clinical implications, Blood, 2013, 121, 1712-1719.

393 A. Ramanathan and N. Karuri, Fibronectin alters the rate of formation and structure of the fibrin matrix, Biochem. Biophys. Res. Commun., 2014, 443, 395-399.

394 V. Reyhani, P. Seddigh, B. Guss, R. Gustafsson, L. Rask and K. Rubin, Fibrin binds to collagen and provides a bridge for alphaVbeta3 integrin-dependent contraction of collagen gels, Biochem. J., 2014, 462, 113-123.

395 C. M. Rowland, C. R. Pullinger, M. M. Luke, D. Shiffman, L. Green, I. Movsesyan, J. J. Devlin, M. J. Malloy, J. P. Kane and A. Undas, Lipoprotein (a), LPA Ile4399Met, and Fibrin Clot Properties, Thromb. Res., 2014, 133, 863-867.

396 J. Jankun, P. Landeta, E. Pretorius, E. Skrzypczak-Jankun and B. Lipinski, Unusual clotting dynamics of plasma supplemented with iron(III), Int. J. Mol. Med., 2014, 33, 367-372.

397 B. Blombäck, Fibrinogen structure, activation, polymerization and fibrin gel structure, Thromb. Res., 1994, 75, 327-328.

398 M. S. Kostelansky, K. C. Lounes, L. F. Ping, S. K. Dickerson, O. V. Gorkun and S. T. Lord, Calcium-binding site beta 2, adjacent to the "b" polymerization site, modulates lateral aggregation of protofibrils during fibrin polymerization, Biochemistry, 2004, 43, 2475-2483.

399 M. S. Kostelansky, K. C. Lounes, L. F. Ping, S. K. Dickerson, O. V. Gorkun and S. T. Lord, Probing the gamma2 calciumbinding site: studies with gammaD298,301A fibrinogen reveal changes in the gamma294-301 loop that alter the integrity of the "a" polymerization site, Biochemistry, 2007, 46, 5114-5123.

400 M. D. Bale, L. G. Westrick and D. F. Mosher, Incorporation of thrombospondin into fibrin clots, J. Biol. Chem., 1985, 260, 7502-7508.

401 M. D. Bale and D. F. Mosher, Effects of thrombospondin on fibrin polymerization and structure, J. Biol. Chem., 1986, 261, 862-868.

402 M. D. Bale, Noncovalent and covalent interactions of thrombospondin with polymerizing fibrin, Semin. Thromb. Hemostasis, 1987, 13, 326-334.

403 P. Hopmeier, M. Halbmayer, M. Fischer and G. Marx, Zinc modulates thrombin adsorption to fibrin, Thromb. Res., 1990, 58, 293-301.

404 G. Marx, P. Hopmeier and D. Gurfel, Zinc alters fibrin ultrastructure, Thromb. Haemostasis, 1987, 57, 73-76.

405 G. Marx and P. Hopmeier, Zinc inhibits FPA release and increases fibrin turbidity, Am. J. Hematol., 1986, 22, 347-353.

406 V. G. Nielsen and E. Pretorius, Iron Enhanced Coagulation is Attenuated by Chelation: A Thrombelastographic and Ultrastructural Analysis, Blood Coagulation Fibrinolysis, 2014, DOI: 10.1097/MBC.0000000000000160.

407 B. Lipinski, Hydroxyl radical and its scavengers in health and disease, Oxid. Med. Cell. Longevity, 2011, 2011, 809696.

408 B. Lipinski and E. Pretorius, Hydroxyl radical-modified fibrinogen as a marker of thrombosis: the role of iron, Hematology, 2012, 17, 241-247. 
409 G. Rimbach, J. Pallauf, J. Moehring, K. Kraemer and A. M. Minihane, Effect of dietary phytate and microbial phytase on mineral and trace element bioavailability: a literature review, Curr. Top. Nutraceutical Res., 2008, 6, 131-144.

410 Y. Won, Force Field for Monovalent, Divalent, and Trivalent Cations Developed under the Solvent Boundary Potential, J. Phys. Chem. A, 2012, 116, 11763-11767.

411 F. J. Zhang, F. Roosen-Runge, A. Sauter, M. Wolf, R. M. J. Jacobs and F. Schreiber, Reentrant condensation, liquid-liquid phase separation and crystallization in protein solutions induced by multivalent metal ions, Pure Appl. Chem., 2014, 86, 191-202.

412 G. Rimbach and J. Pallauf, Phytic acid inhibits free radical formation in vitro but does not affect liver oxidant or antioxidant status in growing rats, J. Nutr., 1998, 128, 1950-1955.

413 M. A. Kohanski, M. A. DePristo and J. J. Collins, Sublethal antibiotic treatment leads to multidrug resistance via radical-induced mutagenesis, Mol. Cell, 2010, 37, 311-320.

414 F. Ruipérez, J. I. Mujika, J. M. Ugalde, C. Exley and X. Lopez, Pro-oxidant activity of aluminum: promoting the Fenton reaction by reducing $\mathrm{Fe}(\mathrm{III})$ to $\mathrm{Fe}(\mathrm{II}), \mathrm{J}$. Inorg. Biochem., 2012, 117, 118-123.

415 C. Exley, The coordination chemistry of aluminium in neurodegenerative disease, Coord. Chem. Rev., 2012, 256, 2142-2146.

416 M. Hoffman, Alterations of fibrinogen structure in human disease, Cardiovasc. Hematol. Agents Med. Chem., 2008, 6, 206-211.

417 M. Pieters, N. Covic, T. Loots du, F. H. van der Westhuizen, D. G. van Zyl, P. Rheeder, J. C. Jerling and J. W. Weisel, The effect of glycaemic control on fibrin network structure of type 2 diabetic subjects, Thromb. Haemostasis, 2006, 96, 623-629.

418 M. Pieters, N. Covic, F. H. van der Westhuizen, C. Nagaswami, Y. Baras, D. Toit Loots, J. C. Jerling, D. Elgar, K. S. Edmondson, D. G. van Zyl, P. Rheeder and J. W. Weisel, Glycaemic control improves fibrin network characteristics in type 2 diabetes - a purified fibrinogen model, Thromb. Haemostasis, 2008, 99, 691-700.

419 A. C. Swanepoel, B. G. Lindeque, P. J. Swart, Z. Abdool and E. Pretorius, Estrogen causes ultrastructural changes of fibrin networks during the menstrual cycle: a qualitative investigation, Microsc. Res. Tech., 2014, 77, 594-601.

420 A. C. Swanepoel, B. G. Lindeque, P. J. Swart, Z. Abdool and E. Pretorius, Ultrastructural changes of fibrin networks during three phases of pregnancy: a qualitative investigation, Microsc. Res. Tech., 2014, 77, 602-608.

421 I. Dalle-Donne, A. Scaloni, D. Giustarini, E. Cavarra, G. Tell, G. Lungarella, R. Colombo, R. Rossi and A. Milzani, Proteins as biomarkers of oxidative/nitrosative stress in diseases: The contribution of redox proteomics, Mass Spectrom. Rev., 2005, 24, 55-99.

422 I. Dalle-Donne, R. Rossi, R. Colombo, D. Giustarini and A. Milzani, Biomarkers of oxidative damage in human disease, Clin. Chem., 2006, 52, 601-623.
423 A. Bachi, I. Dalle-Donne and A. Scaloni, Redox proteomics: chemical principles, methodological approaches and biological/biomedical promises, Chem. Rev., 2013, 113, 596-698.

424 D. A. Butterfield and I. Dalle-Donne, Redox Proteomics: From Protein Modifications to Cellular Dysfunction and Disease, Mass Spectrom. Rev., 2014, 33, 1-6.

425 V. G. Nielsen, J. P. Crow, F. Zhou and D. A. Parks, Peroxynitrite inactivates tissue plasminogen activator, Anesth. Analg., 2004, 98, 1312-1317, table of contents.

426 I. Parastatidis, L. Thomson, A. Burke, I. Chernysh, C. Nagaswami, J. Visser, S. Stamer, D. C. Liebler, G. Koliakos, H. F. Heijnen, G. A. Fitzgerald, J. W. Weisel and $\mathrm{H}$. Ischiropoulos, Fibrinogen beta-chain tyrosine nitration is a prothrombotic risk factor, J. Biol. Chem., 2008, 283, 33846-33853.

427 Y. Ding, Y. Luo and J. Fu, Effects of Mn (II) on peroxynitrite nitrifying fibrinogen, Bio-Med. Mater. Eng., 2014, 24, 901-907.

428 E. A. Hod, G. M. Brittenham, G. B. Billote, R. O. Francis, Y. Z. Ginzburg, J. E. Hendrickson, J. Jhang, J. Schwartz, S. Sharma, S. Sheth, A. N. Sireci, H. L. Stephens, B. A. Stotler, B. S. Wojczyk, J. C. Zimring and S. L. Spitalnik, Transfusion of human volunteers with older, stored red blood cells produces extravascular hemolysis and circulating non-transferrin-bound iron, Blood, 2011, 118, 6675-6682.

429 E. A. Hod and S. L. Spitalnik, Stored red blood cell transfusions: Iron, inflammation, immunity, and infection, Transfus. Clin. Biol., 2012, 19, 84-89.

430 D. Wang, J. Sun, S. B. Solomon, H. G. Klein and C. Natanson, Transfusion of older stored blood and risk of death: a meta-analysis, Transfusion, 2012, 52, 1184-1195.

431 C. Aubron, A. Nichol, D. J. Cooper and R. Bellomo, Age of red blood cells and transfusion in critically ill patients, Ann. Intensive Care, 2013, 3, 2.

432 L. T. Goodnough, J. H. Levy and M. F. Murphy, Concepts of blood transfusion in adults, Lancet, 2013, 381, 1845-1854.

433 A. C. Hubbard, S. Bandyopadhyay, B. S. Wojczyk, S. L. Spitalnik, E. A. Hod and K. A. Prestia, Effect of dietary iron on fetal growth in pregnant mice, Comp. Med., 2013, 63, 127-135.

434 S. B. Solomon, D. Wang, J. Sun, T. Kanias, J. Feng, C. C. Helms, M. A. Solomon, M. Alimchandani, M. Quezado, M. T. Gladwin, D. B. Kim-Shapiro, H. G. Klein and C. Natanson, Mortality increases after massive exchange transfusion with older stored blood in canines with experimental pneumonia, Blood, 2013, 121, 1663-1672.

435 A. Shander and L. T. Goodnough, Can blood transfusion be not only ineffective, but also injurious?, Ann. Thorac. Surg., 2014, 97, 11-14.

436 L. T. Goodnough, Iron-related adverse effects from stored blood, Blood, 2014, 123, 1287-1289.

437 I. Cortés-Puch, D. Wang, J. Sun, S. B. Solomon, K. E. Remy, M. Fernandez, J. Feng, T. Kanias, L. Bellavia, D. Sinchar, A. Perlegas, M. A. Solomon, W. E. Kelley, M. A. Popovsky, M. T. Gladwin, D. B. Kim-Shapiro, H. G. Klein and 
C. Natanson, Washing older blood units before transfusion reduces plasma iron and improves outcomes in experimental canine pneumonia, Blood, 2014, 123, 1403-1411.

438 D. Wang, I. Cortés-Puch, J. Sun, S. B. Solomon, T. Kanias, K. E. Remy, J. Feng, M. Alimchandani, M. Quezado, C. Helms, A. Perlegas, M. T. Gladwin, D. B. Kim-Shapiro, H. G. Klein and C. Natanson, Transfusion of older stored blood worsens outcomes in canines depending on the presence and severity of pneumonia, Transfusion, 2014, 54, 1712-1724.

439 L. Katsimpardi, N. K. Litterman, P. A. Schein, C. M. Miller, F. S. Loffredo, G. R. Wojtkiewicz, J. W. Chen, R. T. Lee, A. J. Wagers and L. L. Rubin, Vascular and neurogenic rejuvenation of the aging mouse brain by young systemic factors, Science, 2014, 344, 630-634.

440 S. A. Villeda, K. E. Plambeck, J. Middeldorp, J. M. Castellano, K. I. Mosher, J. Luo, L. K. Smith, G. Bieri, K. Lin, D. Berdnik, R. Wabl, J. Udeochu, E. G. Wheatley, B. Zou, D. A. Simmons, X. S. Xie, F. M. Longo and T. Wyss-Coray, Young blood reverses age-related impairments in cognitive function and synaptic plasticity in mice, Nat. Med., 2014.

441 P. J. Nestel, N. Straznicky, N. A. Mellett, G. Wong, D. P. De Souza, D. L. Tull, C. K. Barlow, M. T. Grima and P. J. Meikle, Specific plasma lipid classes and phospholipid fatty acids indicative of dairy food consumption associate with insulin sensitivity, Am. J. Clin. Nutr., 2014, 99, 46-53.

442 M. B. Andresdottir, N. Sigfusson, H. Sigvaldason and V. Gudnason, Erythrocyte sedimentation rate, an independent predictor of coronary heart disease in men and women - The Reykjavik study, Am. J. Epidemiol., 2003, 158, 844-851.

443 J. Crawford, M. K. Eye-Boland and H. J. Cohen, Clinical utility of erythrocyte sedimentation rate and plasma protein analysis in the elderly, Am. J. Med., 1987, 82, 239-246.

444 G. Erikssen, K. Liestol, J. V. Bjornholt, H. Stormorken, E. Thaulow and J. Erikssen, Erythrocyte sedimentation rate: a possible marker of atherosclerosis and a strong predictor of coronary heart disease mortality, Eur. Heart J., 2000, 21, 1614-1620.

445 T. A. Kermani, J. Schmidt, C. S. Crowson, S. R. Ytterberg, G. G. Hunder, E. L. Matteson and K. J. Warrington, Utility of erythrocyte sedimentation rate and C-reactive protein for the diagnosis of giant cell arteritis, Semin. Arthritis Rheum., 2012, 41, 866-871.

446 M. Pavlović, D. Babić, P. Rastović and I. Ljevak, Association of erythrocyte sedimentation rate and fibrinogen concentration with metabolic syndrome in schizophrenic patients, Psychiatr. Danubina, 2013, 25(suppl 1), 51-55.

447 S. Yardim-Akaydin, E. Caliskan-Can, H. Firat, S. Ardic and B. Simsek, Influence of Gender on C-Reactive Protein, Fibrinogen, and Erythrocyte Sedimentation Rate in Obstructive Sleep Apnea, Anti-Inflammatory Anti-Allergy Agents Med. Chem., 2014, 13, 56-63.

448 I. Yildirim, E. Hur and F. Kokturk, Inflammatory Markers: C-Reactive Protein, Erythrocyte Sedimentation Rate, and
Leukocyte Count in Vitamin D Deficient Patients with and without Chronic Kidney Disease, Int. J. Endocrinol., 2013, 2013, 802165.

449 F. J. Neumann, H. A. Katus, E. Hoberg, P. Roebruck, M. Braun, H. M. Haupt, H. Tillmanns and W. Kübler, Increased plasma viscosity and erythrocyte aggregation: indicators of an unfavourable clinical outcome in patients with unstable angina pectoris, Br. Heart J., 1991, 66, 425-430.

450 A. Luquita, L. Urli, M. J. Svetaz, A. M. Gennaro, R. Volpintesta, S. Palatnik and M. Rasia, Erythrocyte aggregation in rheumatoid arthritis: Cell and plasma factor's role, Clin. Hemorheol. Microcirc., 2009, 41, 49-56.

451 M. Piagnerelli, K. Z. Boudjeltia, M. Vanhaeverbeek and J. L. Vincent, Red blood cell rheology in sepsis, Intensive Care Med., 2003, 29, 1052-1061.

452 N. Bolokadze, I. Lobjanidze, N. Momtselidze, R. Shakarishvili and G. Mchedlishvili, Comparison of erythrocyte aggregability changes during ischemic and hemorrhagic stroke, Clin. Hemorheol. Microcirc., 2006, 35, 265-267.

453 in Handbook of Hemorheology and Hemodynamics, ed. O. K. Baskurt, M. R. Hardeman, M. W. Rampling and H. J. Meiselman, IOS Press, Amsterdam, 2007.

454 O. Baskurt, B. Neu and H. J. Meiselman, Red Blood Cell Aggregation, CRC Press, Boca Raton, 2011.

455 M. R. Hardeman, P. T. Goedhart, J. G. G. Dobbe and K. P. Lettinga, Laser-Assisted Optical Rotational Cell Analyzer (Lorca). 1. A New Instrument for Measurement of Various Structural Hemorheological Parameters, Clin. Hemorheol., 1994, 14, 605-618.

456 M. R. Hardeman, P. T. Goedhart and N. H. Schut, LaserAssisted Optical Rotational Cell Analyzer (Lorca). 2. RedBlood-Cell Deformability - Elongation Index Versus Cell Transit-Time, Clin. Hemorheol., 1994, 14, 619-630.

457 M. R. Hardeman, J. G. Dobbe and C. Ince, The Laser-assisted Optical Rotational Cell Analyzer (LORCA) as red blood cell aggregometer, Clin. Hemorheol. Microcirc., 2001, 25, 1-11.

458 M. R. Hardeman, G. A. J. Besselink, I. Ebbing, D. de Korte, C. Ince and A. J. Verhoeven, Laser-assisted optical rotational cell analyzer measurements reveal early changes in human RBC deformability induced by photodynamic treatment, Transfusion, 2003, 43, 1533-1537.

459 J. Bester, A. V. Buys, B. Lipinski, D. B. Kell and E. Pretorius, High ferritin levels have major effects on the morphology of erythrocytes in Alzheimer's disease, Front. Aging Neurosci., 2013, 5, 00088.

460 A. V. Buys, M. J. Van Rooy, P. Soma, D. Van Papendorp, B. Lipinski and E. Pretorius, Changes in red blood cell membrane structure in type 2 diabetes: a scanning electron and atomic force microscopy study, Cardiovasc. Diabetol., 2013, 12, 25.

461 J. N. Du Plooy, A. Buys, W. Duim and E. Pretorius, Comparison of platelet ultrastructure and elastic properties in thrombo-embolic ischemic stroke and smoking using atomic force and scanning electron microscopy, PLoS One, 2013, 8, e69774. 
462 E. Pretorius, J. N. du Plooy, P. Soma, I. Keyser and A. V. Buys, Smoking and fluidity of erythrocyte membranes: A high resolution scanning electron and atomic force microscopy investigation, Nitric Oxide, 2013, 35C, 42-46.

463 W. J. van der Spuy and E. Pretorius, Interaction of red blood cells adjacent to and within a thrombus in experimental cerebral ischaemia, Thromb. Res., 2013, 132, 718-723.

464 M. E. Emans, C. A. J. M. Gaillard, R. Pfister, M. W. Tanck, S. M. Boekholdt, N. J. Wareham and K. T. Khaw, Red cell distribution width is associated with physical inactivity and heart failure, independent of established risk factors, inflammation or iron metabolism; the EPIC-Norfolk study, Int. J. Cardiol., 2013, 168, 3550-3555.

465 Z. Förhécz, T. Gombos, G. Borgulya, Z. Pozsonyi, Z. Prohászka and L. Jánoskuti, Red cell distribution width in heart failure: prediction of clinical events and relationship with markers of ineffective erythropoiesis, inflammation, renal function, and nutritional state, Am. Heart J., 2009, 158, 659-666.

466 Z. A. Öztürk, A. Ünal, R. Yiğiter, Y. Yesil, M. E. Kuyumcu, M. Neyal and Y. Kepekçi, Is increased red cell distribution width (RDW) indicating the inflammation in Alzheimer's disease (AD)?, Arch. Gerontol. Geriatr., 2013, 56, 50-54.

467 K. Shrestha, A. G. Borowski, R. W. Troughton, A. L. Klein and W. H. Tang, Association between systemic neutrophil gelatinase-associated lipocalin and anemia, relative hypochromia, and inflammation in chronic systolic heart failure, Congestive Heart Failure, 2012, 18, 239-244.

468 L. A. Allen, G. M. Felker, M. R. Mehra, J. R. Chiong, S. H. Dunlap, J. K. Ghali, D. J. Lenihan, R. M. Oren, L. E. Wagoner, T. A. Schwartz and K. F. Adams, Jr., Validation and potential mechanisms of red cell distribution width as a prognostic marker in heart failure, J. Card. Failure, 2010, 16, 230-238.

469 Y. Koma, A. Onishi, H. Matsuoka, N. Oda, N. Yokota, Y. Matsumoto, M. Koyama, N. Okada, N. Nakashima, D. Masuya, H. Yoshimatsu and Y. Suzuki, Increased red blood cell distribution width associates with cancer stage and prognosis in patients with lung cancer, PLoS One, 2013, 8, e80240.

470 W. S. Lee and T. Y. Kim, Relation between red blood cell distribution width and inflammatory biomarkers in rheumatoid arthritis, Arch. Pathol. Lab. Med., 2010, 134, 505-506.

471 G. Lippi, G. Targher, M. Montagnana, G. L. Salvagno, G. Zoppini and G. C. Guidi, Relation between red blood cell distribution width and inflammatory biomarkers in a large cohort of unselected outpatients, Arch. Pathol. Lab. Med., 2009, 133, 628-632.

472 M. Montagnana, G. Cervellin, T. Meschi and G. Lippi, The role of red blood cell distribution width in cardiovascular and thrombotic disorders, Clin. Chem. Lab. Med., 2012, 50, 635-641.

473 C. S. Song, D. I. Park, M. Y. Yoon, H. S. Seok, J. H. Park, H. J. Kim, Y. K. Cho, C. I. Sohn, W. K. Jeon and B. I. Kim, Association between red cell distribution width and disease activity in patients with inflammatory bowel disease, Dig. Dis. Sci., 2012, 57, 1033-1038.

474 A. Vaya, J. L. Hernández, E. Zorio and D. Bautista, Association between red blood cell distribution width and the risk of future cardiovascular events, Clin. Hemorheol. Microcirc., 2012, 50, 221-225.

475 A. S. Lapedes, B. G. Giraud, L. C. Liu and G. D. Stormo, Correlated mutations in models of protein sequences: phylogenetic and structural effects, IMS Lect. Notes, 1999, 33, 236-256.

$476 \mathrm{H}$. Ashkenazy and Y. Kliger, Reducing phylogenetic bias in correlated mutation analysis, PEDS, 2010, 23, 321-326.

477 D. S. Marks, L. J. Colwell, R. Sheridan, T. A. Hopf, A. Pagnani, R. Zecchina and C. Sander, Protein 3D structure computed from evolutionary sequence variation, $P L O S$ One, 2011, 6, e28766.

478 D. T. Jones, D. W. Buchan, D. Cozzetto and M. Pontil, PSICOV: Precise structural contact prediction using sparse inverse covariance estimation on large multiple sequence alignments, Bioinformatics, 2012, 28, 184-190.

479 D. S. Marks, T. A. Hopf and C. Sander, Protein structure prediction from sequence variation, Nat. Biotechnol., 2012, 30, 1072-1080.

480 T. Kosciolek and D. T. Jones, De novo structure prediction of globular proteins aided by sequence variation-derived contacts, PLoS One, 2014, 9, e92197.

481 A. Yasim, M. Kilinc, M. Aral, H. Oksuz, M. Kabalci, E. Eroglu and S. Imrek, Serum concentration of procoagulant, endothelial and oxidative stress markers in early primary varicose veins, Phlebology, 2008, 23, 15-20.

482 H. Yang, H. J. Ko, J. Y. Yang, J. J. Kim, S. U. Seo, S. G. Park, S. S. Choi, J. K. Seong and M. N. Kweon, Interleukin-1 promotes coagulation, which is necessary for protective immunity in the lung against Streptococcus pneumoniae infection, J. Infect. Dis., 2013, 207, 50-60.

483 M. N. Mannila, P. Eriksson, K. Leander, B. Wiman, U. de Faire, A. Hamsten and A. Silveira, The association between fibrinogen haplotypes and myocardial infarction in men is partly mediated through pleiotropic effects on the serum IL-6 concentration, J. Intern. Med., 2007, 261, 138-147.

484 Z. X. Zhang, N. L. Fuentes and G. M. Fuller, Characterization of the Il-6 Responsive Elements in the GammaFibrinogen Gene Promoter, J. Biol. Chem., 1995, 270, 24287-24291.

485 S. Ohta, M. Okazaki, M. Maruyama and K. Oguchi, Involvement of IL-6 and IL-6 receptor in fibrinogen synthesis in the liver of triton WR-1339-induced hyperlipidemic rats, In Vivo, 2004, 18, 203-211.

486 Y. Ohsugi, Recent advances in immunopathophysiology of interleukin-6: an innovative therapeutic drug, tocilizumab (recombinant humanized anti-human interleukin-6 receptor antibody), unveils the mysterious etiology of immunemediated inflammatory diseases, Biol. Pharm. Bull., 2007, 30, 2001-2006.

487 H. O. Duan and P. J. Simpson-Haidaris, Functional analysis of interleukin 6 response elements (IL-6REs) on the human 
gamma-fibrinogen promoter: binding of hepatic Stat3 correlates negatively with transactivation potential of type II IL-6REs, J. Biol. Chem., 2003, 278, 41270-41281.

488 H. O. Duan and P. J. Simpson-Haidaris, Cell type-specific differential induction of the human gamma-fibrinogen promoter by interleukin-6, J. Biol. Chem., 2006, 281, 12451-12457.

489 C. L. Carty, P. Heagerty, S. R. Heckbert, G. P. Jarvik, L. A. Lange, M. Cushman, R. P. Tracy and A. P. Reiner, Interaction between Fibrinogen and IL-6 Genetic Variants and Associations with Cardiovascular Disease Risk in the Cardiovascular Health Study, Ann. Hum. Genet., 2010, 74, 1-10.

490 D. I. Swerdlow, M. V. Holmes, K. B. Kuchenbaecker, J. E. L. Engmann, T. Shah, R. Sofat, Y. R. Guo, C. Chung, A. Peasey, R. P. Ster, S. P. Mooijaart, H. A. Ireland, M. Leusink, C. Langenberg, K. Li, J. Palmen, P. Howard, J. A. Cooper, F. Drenos, J. Hardy, M. A. Nalls, Y. R. Li, G. Lowe, M. Stewart, S. J. Bielinski, J. Peto, N. J. Timpson, J. Gallacher, M. Dunlop, R. Houlston, I. Tomlinson, I. Tzoulaki, J. Luan, J. M. A. Boer, N. G. Forouhi, N. C. Onland-Moret, Y. T. van der Schouw, R. B. Schnabel, J. A. Hubacek, R. Kubinova, M. Baceviciene, A. Tamosiunas, A. Pajak, R. Topor-Madry, S. A. Malyutina, D. Baldassarre, B. Sennblad, E. Tremoli, U. de Faire, L. Ferrucci, S. Bandenelli, T. Tanaka, J. F. Meschia, A. Singleton, G. Navis, I. M. Leach, S. J. L. Bakker, R. T. Gansevoort, I. Ford, S. E. Epstein, M. S. Burnett, J. M. Devaney, J. W. Jukema, R. G. J. Westendorp, G. J. de Borst, Y. van der Graaf, P. A. de Jong, A. H. Maitland-van der Zee, O. H. Klungel, A. de Boer, P. A. Doevendans, J. W. Stephens, C. B. Eaton, J. G. Robinson, J. E. Manson, F. G. R. Fowkes, T. M. Frayling, J. F. Price, P. H. Whincup, R. W. Morris, D. A. Lawlor, G. D. Smith, Y. Ben-Shlomo, S. Redline, L. A. Lange, M. Kumari, N. J. Wareham, W. M. M. Verschuren, E. J. Benjamin, J. C. Whittaker, A. Hamsten, F. Dudbridge, J. A. C. Delaney, A. Wong, D. Kuh, R. Hardy, B. A. Castillo, J. J. Connolly, P. van der Harst, E. J. Brunner, M. G. Marmot, C. L. Wassel, S. E. Humphries, P. J. Talmud, M. Kivimaki, F. W. Asselbergs, M. Voevoda, M. Bobak, H. Pikhart, J. G. Wilson, H. Hakonarson, A. P. Reiner, B. J. Keating, N. Sattar, A. D. Hingorani and J. P. Casas, I.-R. M. R The interleukin-6 receptor as a target for prevention of coronary heart disease: a mendelian randomisation analysis, Lancet, 2012, 379, 1214-1224.

491 E. Nemeth, S. Rivera, V. Gabayan, C. Keller, S. Taudorf, B. K. Pedersen and T. Ganz, IL-6 mediates hypoferremia of inflammation by inducing the synthesis of the iron regulatory hormone hepcidin, J. Clin. Invest., 2004, 113, 1271-1276.

492 N. V. Gorbunov, S. J. McFaul, A. Januszkiewicz and J. L. Atkins, Pro-inflammatory alterations and status of blood plasma iron in a model of blast-induced lung trauma, Int. J. Immunopathol. Pharmacol., 2005, 18, 547-556.

493 R. G. DePalma, V. W. Hayes, B. K. Chow, G. Shamayeva, P. E. May and L. R. Zacharski, Ferritin levels, inflammatory biomarkers, and mortality in peripheral arterial disease: A substudy of the Iron (Fe) and Atherosclerosis Study (FeAST) Trial, J. Vasc. Surg., 2010, 51, 1498-1503.
494 F. Marques, A. M. Falcao, J. C. Sousa, G. Coppola, D. Geschwind, N. Sousa, M. Correia-Neves and J. A. Palha, Altered iron metabolism is part of the choroid plexus response to peripheral inflammation, Endocrinology, 2009, 150, 2822-2828.

495 K. Broedbaek, V. Siersma, J. T. Andersen, M. Petersen, S. Afzal, B. Hjelvang, A. Weimann, R. D. Semba, L. Ferrucci and H. E. Poulsen, The association between low-grade inflammation, iron status and nucleic acid oxidation in the elderly, Free Radical Res., 2011, 45, 409-416.

496 S. Uysal, F. Armutcu, T. Aydogan, K. Akin, M. Ikizek and M. R. Yigitoglu, Some inflammatory cytokine levels, iron metabolism and oxidan stress markers in subjects with nonalcoholic steatohepatitis, Clin. Biochem., 2011, 44, 1375-1379.

497 A. C. Chua, B. R. Klopcic, D. S. Ho, S. K. Fu, C. H. Forrest, K. D. Croft, J. K. Olynyk, I. C. Lawrance and D. Trinder, Dietary Iron Enhances Colonic Inflammation and IL-6/IL11-Stat3 Signaling Promoting Colonic Tumor Development in Mice, PLoS One, 2013, 8, e78850.

498 J. López-Prieto, E. González-Reimers, M. R. Alemán-Valls, M. J. de la Vega-Prieto, P. Abreu-González, R. PelazasGonzález, R. Hernández-Luis, C. Jorge-Ripper and F. Santolaria-Fernández, Iron and proinflammatory cytokines in chronic hepatitis $\mathrm{C}$ virus infection, Biol. Trace Elem. Res., 2013, 155, 5-10.

499 S.-N. J. Song, M. Iwahashi, N. Tomosugi, K. Uno, J. Yamana, S. Yamana, T. Isobe, H. Ito, H. Kawabata and K. Yoshizaki, Comparative evaluation of the effects of treatment with tocilizumab and TNF-alpha inhibitors on serum hepcidin, anemia response and disease activity in rheumatoid arthritis patients, Arthritis Res. Ther., 2013, 15, R141.

500 L. A. Borthwick, T. A. Wynn and A. J. Fisher, Cytokine mediated tissue fibrosis, Biochim. Biophys. Acta, 2013, 1832, 1049-1060.

501 R. C. Chambers and G. J. Laurent, Coagulation cascade proteases and tissue fibrosis, Biochem. Soc. Trans., 2002, 30, 194-200.

502 B. D. Bringardner, C. P. Baran, T. D. Eubank and C. B. Marsh, The role of inflammation in the pathogenesis of idiopathic pulmonary fibrosis, Antioxid. Redox Signaling, 2008, 10, 287-301.

503 R. C. Chambers, Procoagulant signalling mechanisms in lung inflammation and fibrosis: novel opportunities for pharmacological intervention?, Br. J. Pharmacol., 2008, 153(suppl 1), S367-S378.

504 T. A. Wynn and T. R. Ramalingam, Mechanisms of fibrosis: therapeutic translation for fibrotic disease, Nat. Med., 2012, 18, 1028-1040.

505 J. S. Duffield, M. Lupher, V. J. Thannickal and T. A. Wynn, Host responses in tissue repair and fibrosis, Annu. Rev. Pathol.: Mech. Dis., 2013, 8, 241-276.

506 P. F. Mercer and R. C. Chambers, Coagulation and coagulation signalling in fibrosis, Biochim. Biophys. Acta, 2013, 1832, 1018-1027.

507 V. Aggarwal, P. M. Kapoor, M. Choudhury, U. Kiran and U. Chowdhury, Utility of Sonoclot analysis and tranexamic acid in tetralogy of Fallot patients undergoing intracardiac repair, Ann. Card. Anaesth., 2012, 15, 26-31. 